\title{
الأسس العامة لبناء برامج تعليم اللغة العربية للطفل فى مرحلة رياض الأطفال
}

\author{
إعداد
}

'الباحثة / نشوى عبد الخالق مصطفى على عطالله'

$$
\text { إشر اف }
$$

أ.د/ كمال الاين حسين

أستاذ الأدب المسرحى و الار كماست الدات الثعبية

كلية التربية للطقولة المبكرة - جامعة القاهرة
أ. د/ محمود كامـل النـاقة

أستاذ المناهج وطرق التدريس كايس

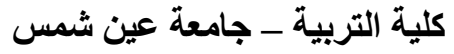

عضو مجمع اللغة العربية

\section{مــتـدمــة}

اللغة أداة الفكر الإنسانى ووسيلة تعبيره ، فالعلاقة بين اللغة والفكر علاقة تلازم ؛ فالتفكير عملية ذهنيةلا يمكن أن تتم إلا باستخدام اللغة، واللغة هى التى تجسد الفكر وتظهره للآخرين، فبدون لغة لا يوجد تفكير ، وبمقدار نمو اللغة لدى الفرد تتمو عملية التفكير لديه .فاللغة والفكر خاضعان لسنة النمو و التطوير ، وحياة اللغة ونمو ها متصل بحيوية الفكر الإنسانى وتقدمه. وتعد مرحلة ما قبل المدرسة مرحلة حاسمة فى حياة الفرد العقلية فهى أهم مر احل التشكيل الذهنى للطفل حيث يكتسب فيها أهم المهار ات ، و الملكات العقلية ، و المعرفية ، و التى تتحدد فيها أيضاً مسار اته التعليمية اللاحقة (جميل الملائكةهـ9 1)

و اللغة تقدم العالم للطفل فى نست تفاعلى لفظى ،وثقافى ، واجتماعى يعيشه الطفل فى محاولة منه لإكتثاف البيئة المحيطة به؛ لذا فالطفل فى هذه المرحلة يمتاز بحبه وشغفه للمعرفة وبناء عدد لا متناهياً من الأفكار ، فيسأل ،و يصف ، ويعبر ،ويتخيل لتنمية خبر اته ومعرفته بالعالم المحيط به ، وسبيله إلى ذللك هى اللغة، و إذا تقدم اللغة العالم للطفل فإن هذا العالم ذاته ـالأسرة و الروضة ـ هو الذى بقدم اللغة للطفل فى صورة منظمة ومنسقة والتى يمارسها مع الطفل بشكل مباشر أو غير مباثر ، وفى تعليم مقصود أو تعلم تلقائى؛ لذا فان الدور الهام المناط برياض الأطفال تقديم اللغة الصحيحة والعمل على تنمية 
مهار اتها ، وزيادة الرصيد اللغوى عند الطفل منها، وإعداده لاستعمالها، وتوظيفها فى المواقف الحياتية

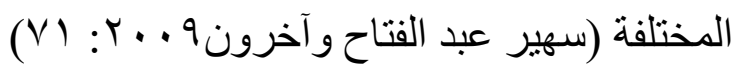

ولتعلم طفل الروضة اللغة العربية دوراً بالغ الأهمية فى هذا الثأن ، فعند إتقانه لمهار اتها و التو اصل بها يتمكن الطفل من فهم بيئته وثقافته العربية والإسلامية التى ينتمى إليها ، ويكتشف الثقافات المغايرة

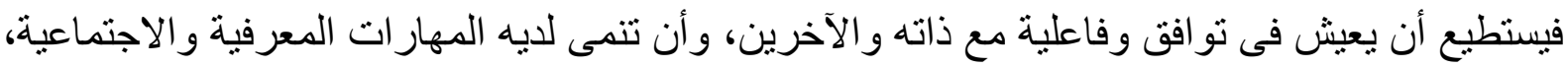

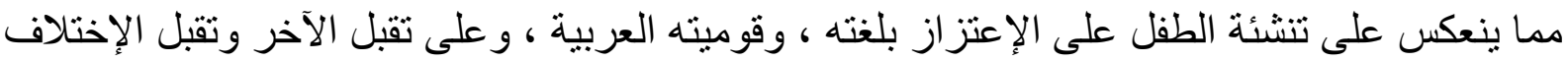

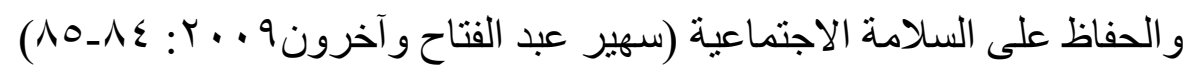

وتعد البرامج التعليمية فى رياض الأطفال أداة التربية فى تحقيق أهدافها، كما تعد التربية أداة

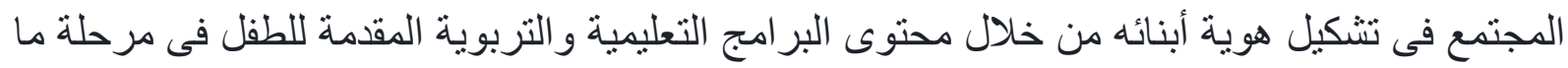
قبل المدرسة ، و المتمثلة فى مجموعة الخبرات و المهار ات التى تقدم للأطفال داخل الروضة وخارجها، ومن ثم فإن التخطيط السليم لبناء برامج رياض الأطفال يستلزم : اختيار محتوى تعليمى وتنظيمه

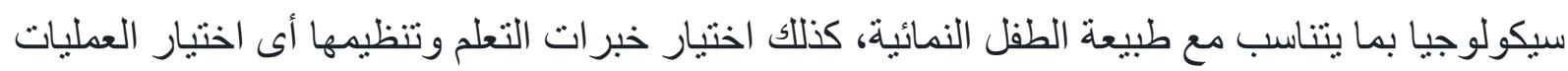
العقلية التى يجب أن يمارسها الطفل عند تنفيذ المحتوى .

وسوف تركز الدراسة الحالية على التوجهات و الأسس العامة لبناء برامج تعليم اللغة العربية للطفل فى مرحلة رياض الأطفال فى ضوء الخصائص النمائية لطفل الروضة، حيث تتناول الدراسة الحالية طبيعة النمو العقلي المعرفي و النمو اللغوي من حيث مفهوم كل منهما، ومر احله، وخصائصها ومظاهره المميزة له في مرحلة رياض الأطفال وذلك لاستخلاص بعض الأسس التي يستند إليها في بناء بر امج تعليم اللغة العربية لطفل الروضة، وتحديد بعض المفاهيم المعرفية التي تتناسب معه، والمتسقة مع طبيعة ن موه العقلي المعرفي و اللغوي.

\section{1 - النمو العقلي المعرفي لطقل الروضة.}

النمو عملية مستمرة، متدرجة، منتظمة، ومتر ابطة تمثل مجموعة من التغييرات و التطور ات المتتابعة المرئية، وغير المرئية تسير حسب نظام متكامل، وتظهر في كل من الجانب التكويني ـ العضوي و الجسمي - و الجانب الوظيفي - نمو الوظائف العقلية، والاجتماعية، و الانفعالية للفرد(راتب

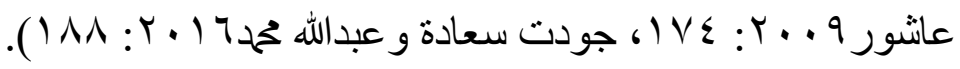

إذن فالنمو العقلي المعرفي هو نمو الوظائف، والعمليات العقلية المختلفة بدءًا من الإدراك الحسي إلى

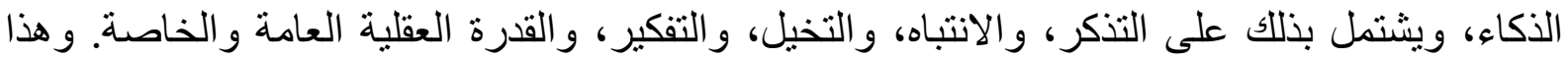


يعني أن مظاهر النمو يمكن ملاحظتها مباشرة أو يستدل عليها من خلال التطور والتغير في أداء الطفل، وسلوكه الناتج عن التفاعل بين ما لايه من استعدادات و إمكانات وبين البيئة التي يتفاعل معها، فيحدث

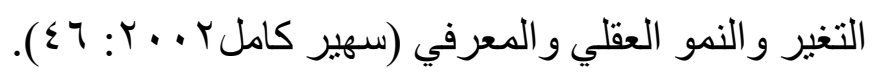

معنى هذا أن الأطفال تنشأ وتتطور لديهم بنى عقلية ومعرفية جديدة؛ نظرًا لنموهم المستمر، حيث إن كل مرحلة عمرية وعقلية تتمايز عن السابقة أو اللاحقة لها بمجموعة من الخصائص المعرفية، فنجد الأطفال تزداد خبراتهم، ومعارفهم، وتنمو قدرتهم على اكتساب المعارف والمعلومات، وقدرتهم على التعلم؛ ذلك لأن عملية النمو تتأثر بالنضج و التعلم، و البيئة المحيطة بهر.

ومن ثم فإن تعليم اللغة العربية لطفل الروضة، و إكسابه بعض المعارف و المفاهيم بتطلب تحقيق التوازن بين البيئة المادية المحيطة به، وبين خبر اته الاجتماعية، ونضجه البيولوجي (عبد الفتاح أبو معال . . . ؟:

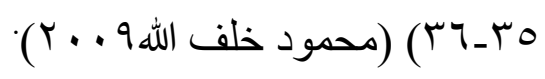

\section{• مراحل النمو العقلي المعرفي لطقل الروضة.}

لمر احل النمو العقلي المعرفي دور مهم في عملية تعليم اللغة العربية لطفل الروضة، فمن خلالها نتعرف طبيعة التعلم لدى هذا الطفل، ونتعرف كيف يحدث النمو المعرفي لديه كما نتعرف على سمات المتعلمين ـ الأطفال، وخصائصهم المعرفية التي تسير في مراحل عقلية منتالية كما حددها بياجيه، والذي يعني بالمرحلة العقلية نمطًا من التر اكيب أو الوحدات، والعمليات العقلية والمفاهيم، والتي تظهر لدى الأطفال في مرحلة عمرية تختلف عنها في مرحلة عمرية أخرى.

معنى هذا أننا يمكن التمبيز بين المراحل العقلية عن طريق التعرف على محتوى كل مرحلة من التر اكيب و الأبنية المعرفية، والمفاهيم، ونتير التر اكيب المعرفية إلى أساليب التفاعل مع البيئة. فكل مرحلة تختلف عن غير ها في أسلوب اكتساب الخبرة، واستيعابها، وتكوين الأبنية المعرفية. و النمو العقلي المعرفي كما حدده بياجيه يمر بأربع مر احل، هي كما ذكر ها(يوسف قطامى . . . ץ: 10بـ $:(r \circ 9$

ا ـ المرحلة الحسية الحركية ( تمتد من الميلاد حتى نهاية السنة الثانية). r - مرحلة ما قبل العمليات (تمتد من السنة الثانية حتى السنة السابعة). r- مرحلة العمليات الحسية (تمتد من السنة السابعة حتى الحادية عشرة). ع- مرحلة العمليات المجردة (تمتد من الحادية عشرة وتستمر ..). 
وبدر اسة هذه المر احل وفحصها توصلت الباحثة إلى أن طفل الروضة يقع في المرحلة العمرية من (ع- ل) سنوات، وتنسب هذه الفترة إلى مرحلة ما قبل العمليات والتي تتناسب خصائصها النمائية مع أطفال الروضة؛ لذا ستقتصر الدراسة الحالية على هذه المرحلة من مراحل النمو العقلي المعرفي عند بياجيه، وفيما يلي عرض لها:

\section{مرحلة ما قبل العمليات (ع - Vسنوات).}

يلاحظ التطور الهائل في الجانب العقلي للطفل في هذه المرحلة فهو ينتقل من المدركات الحسية إلى مستويات عقلية أعلى، بل أنه بعد أن كان "يفكر بحواسه" أي معتمدا في كل المعلومات على استخدام حواسه؛ لاختبار البيئة من حوله، أصبح الآن "يفكر بعقله" حيث تنمو قدرة الطفل فى هذه المرحلة على التطور الذهني للأشياء والأحداث، وبداية التمثيل الرمزي للبيئة من حوله، كذلك يصبح التقليد والمحاكاة هما الأسلوب السلوكي المميز لطفل هذه المرحلة، ويعنى ذلك أن هناك نشاطا معرفيا يحدث استجابة للمثير ات المحيطة بحو اس الطفل، فالطفل لم يكتسب بعد القدرة على القيام بالعمليات العقلية المنطقية التي

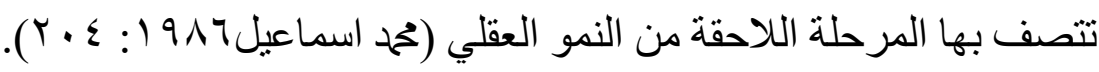
كما تتضمن المرحلة العقلية وجود عمليات عقلية، مثل: ( التذكر ـ التخيلـ الإدرالك ـ الانتباه ـ التفكير ....) كما يتضمن أيضا أي نشاط معرفي يقوم به الطفل ووجود وحدات معرفية تشهم بشكل كبير فى توسعة إدر اكه ونموه العقلي وتمثل الركيزة الأساسية في القيام بالعمليات العقلية، ويستطيع طفل الروضة أن يستخدم جميع وحدات النشاط المعرفي الخمس، وهي:

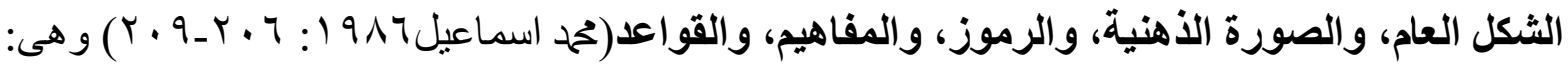
1 - الشكل التصوري العام .

هو طريقة العقل فى تصوير المظاهر المهمة أو الملامح المميزة لحدث ما؛ فنجد عند الطفل الثكل العام عن المسجد مثنا يتمثل فى المأذنة لاعتبار ها أبرز ملامحه الثكلية، ويمكن أن تثكون الأشكال العامة على هي أساس خبر ات حسية أخرى مثل الشم للوردة أو أنواع الطعام أو اللمس للناعم والخشن وهكذا، ولدى الطفل قدرة هائلة على تخزين العديد من الأشكال العامة.

ولابد أن يراعى عند استخدام الوسائل التوضيحية من صور وأفلام ومجسمات لتعليم اللغة العربية، أن تبرز أهم الملامح التي تميز المفردات أو الحروف والدلالات المرتبطة بكل منهما. 


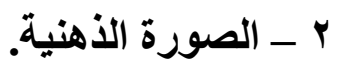

هي تمثيل أكثر تفصيلا، وأكثر وعيا من الثكل العام، فهي تمثل صورة كاملة عن الثيء، و الطفل يستحضر الصورة الذهنية عن الثيء أو الحدث قبل الكلام أو إجابة أسئلة ما أو حل المشكلات البسيطة، فمثلا عند سؤال الطفل: هل للقطة ذيل؟ فلا بد أن يستحضر الصورة الذهنية لديه عن القطة قبل الإجابة. ولابد أن يراعى عند اكساب الطفل مفردات جديدة على محصوله اللغوي أن تكون مصحوبة بصور كاملة عن الأثياء؛ حتى تتكون لدى الطفل الصورة الذهنية التي يستطيع استحضار ها في المواقف الاتصالية ل تلتوظيف اللغة وحل الشكلات.

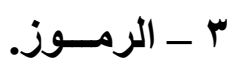

عبارة عن طرق جز افية لتثثيل ـ تصوير ـ أحداث عينية أو صفات الأثياء والأفعال و الخصائص المميزة لها، وهي تختلف عن الأشكال العامة والصور الذهنية التي تعتمد على النواحي المادية لإدراك أك أحداث معينة، والطفل في هذه المرحلة يستطيع أن يتعامل مع الأشياء باعتبار ها رموزا، ويظهر ذللك في أثناء

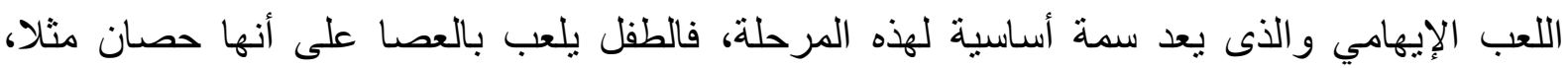

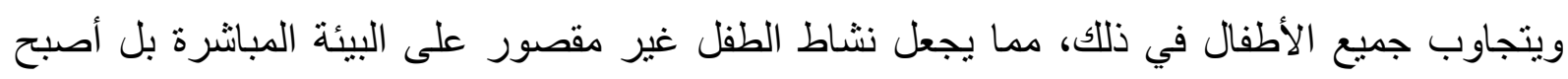
بإمكانه أن يتحدث عن الماضي والمستقبل، ويحصر بياجيه النشاط التخيلي الرمزي للطفل في هذه المرحلة في خمسة أثكال هي: التقليد في غير وجود النموذج، استحضار الصورة الذهنية للأشياء فى ولى لئه حالة غيابها، الرسم التخيلي، اللعب الإيهامي، اللغة (1970.J , (Piaget).

ولابد أن يراعى عند بناء المو اقف التعليمية في برامج تعليم اللغة هذه الخصيصة المميزة لطفل الروضة

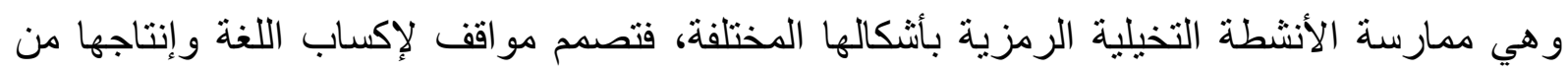
خلال لعب الأدوار و اللعب الإيهامي والتقليد مما يكسب الطفل اللغة العربية من خلال مو اقف اتصالية

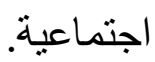

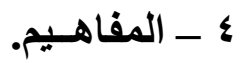

المفهوم هو مجموعة الصفات المشتركة بين أثكال تصويرية عامة أو صور ذهنية أو رموز، ويتبين

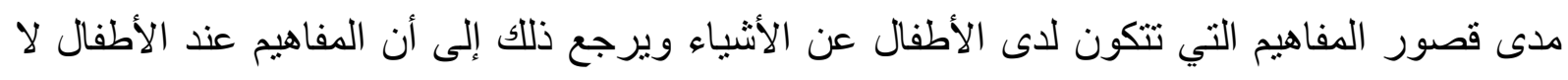

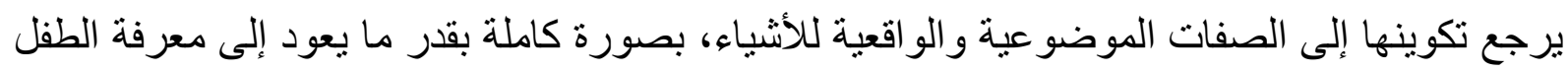

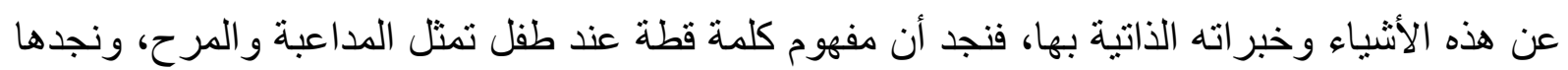
عند طفل آخر ترمز إلى الذعر و الهجوم عليه. 
ومن أهم المفاهيم المعرفية التي يمكن تقديمها لطفل ما قبل المدرسة وفقا لدراسات و أبحاث بياجيه ما يلي:

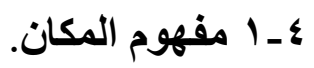

يهتم الأطفال بالعلاقات المكانية للأشياء، وأوضاعهم بالنسبة للأشياء (فوق - تحت - خارج- ...) ويتطور لايهم المفهوم المكاني بدءًا من الصورة العامة للأشياء، ثم مفاهيم الاتجاهات (يمين - شمال ...)، ويتبعهاه

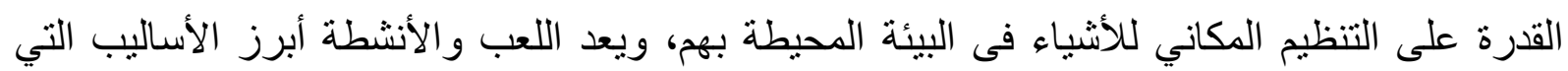

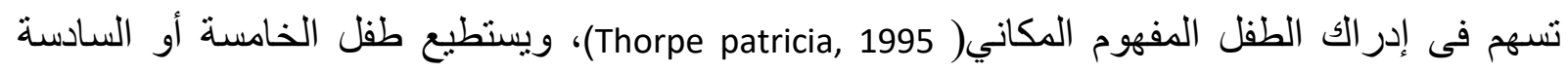
وصف الأماكن التي يتردد عليها (المنزل - الروضة - الحديقة) كذكر اسم الثارع الذى يقطن فيه، و الطرق المؤدية لهذه الأماكن (سعدية بهادر ـ 99 ( ).

فى ضوء ذللك يجب أن يراعى فى بناء برامج تعليم اللغة العربية أن تتضمن إعداد مو اقف حياتية اتصالية

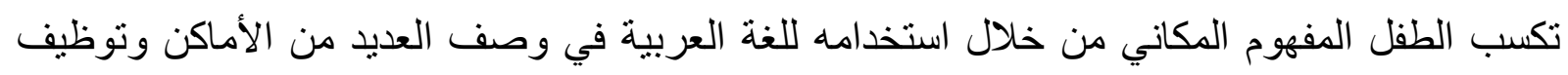
ظرف المكان و المفردات الدالة عليه وفقا للموقف الاتصالي.

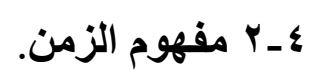

يعد مفهوم الزمن مفهومًا مجردًا أكثر منه مفهومًا حسيًا مما يشكل صعوبة في تعليمه وتعلمه لطفل ما

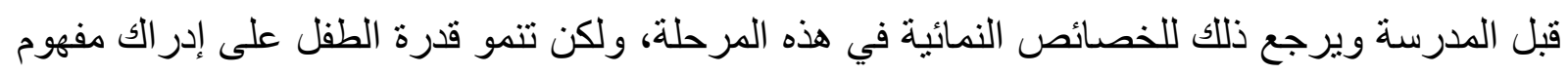

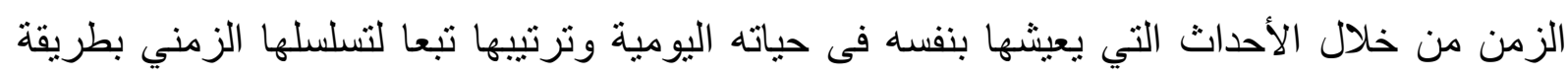

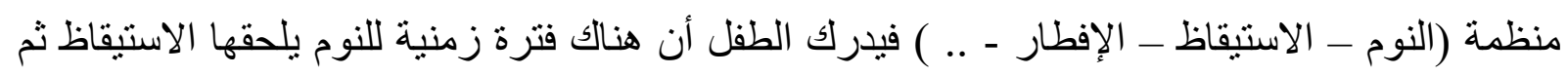
يأتي بعدها فترة زمنية للإفطار و هكذا.

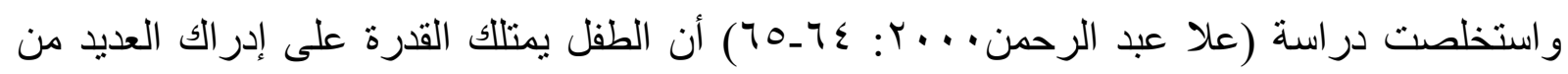

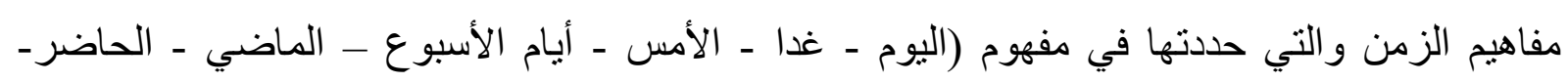

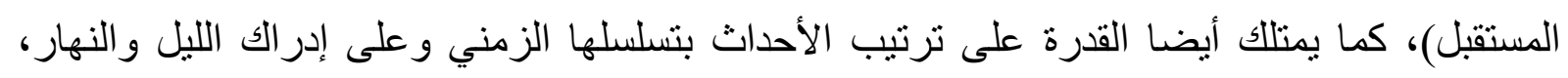
و على تعلم الساعات و أنصاف الساعات و التعرف على فصول السنة، كل ذللك من خلال المظاهر الطبات الطبيعية الحسية المصاحبة للأحداث خلال كل فترة زمنية.

وترى الباحثة أن هنالك ارتباطًا وثثقًا بين إدر الك الطفل لمفهوم الزمن، ونموه اللغوي، فاكتساب الطفل

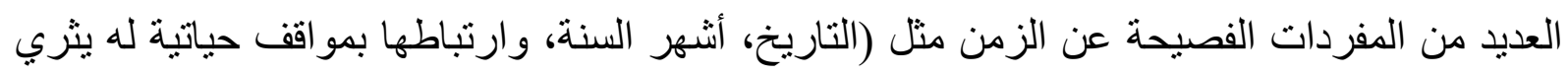
حصيلته اللغوية، وتفكيره للحديث عن هذه المواقف الزمنية الحياتية، وتوظيف الأفعال في أزمنة مختلفة

$$
\text { (الماضي - المستقبل - الحاضر ). }
$$


فى ضوء ذلك يجب أن يراعى فى بناء برامج تعليم اللغة العربية أن تتضمن إعداد مو اقف حياتية اتصالية تكسب الطفل مفهوم الزمن من خلال استخدامه لمفردات اللغة الدالة على الزمن- ظرف زمان - وتوظيفها في وصف العديد من الأحداث في تسلسل زمني.

ع - ب مفهوم العدد.

يصعب على الطفل إدر الك مفهوم العدد بسهولة؛ لأنه مجرد (غير محسوس) يحتاج إلى بعض الخبرات الخاصة من تصنيف الأثياء وتسلسلها وتناظر العناصر العددية أو ترتيبها الذى بسبق إدراك الطفل لمفهوم العدد، وقد توصل بياجيه من خلال بحوثه عن نمو المفاهيم الرياضية عند الأطفال، و إدر اكهم لها (حمح عبد الحليم حسب

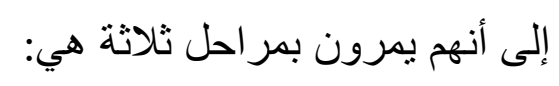
الله

- مرحلة عدم الفهم وتناظر مرحلة ما قبل العمليات. - مرحلة الفهم الجزئي وتناظر مرحلة ما قبل العمليات ومرحلة العمليات المحسوسة. - مرحلة الفهم الكامل وتناظر مرحلة العمليات المحسوسة ومرحلة العمليات الثكلية. وبما أن طفل مرحلة ما قبل المدرسة في مرحلة الفهم الجزئي للأعداد ؛ فإنها يستطيع إدراك التجمعات العددية قبل إدر الك الأعداد ذاتها حيث يؤدي التناظر بين المجموعات العددية إلى إيجاد تكافؤ عددي بين عناصر ها وعليه فإن مفهوم العدد يتحول شيئا فثيئًا من وصف للعناصر والأشياء إلى إدراك العلاقة الكمية بين العدد وعناصره، فأصبح العدد لا يعتمد على التشابه بين الخواص الفزيائية للعناصر مثل اللون، و الحجم، الثكل، .. و إنما على ما يؤديه من معنى ودلالة بالنسبة للطفل خلال الموقف التعليمي، أي إدر الك الطفل للقيمة الفئوية للعدد.

كما أثتتت در اسة (ماجدة محمود صالح 1991 1: AV_Or) ، أن الطفل يمكنه إدراك مفهوم العدد بوضوح إذا أدرك المفاهيم الأولية قبل العددية، وهي متطلبات أساسية سابقة لمفهوم العدد وسوف نتناول تعريف هذه المفاهيم لاستخلاص بعض التوجهات والأسس لبناء برنامج الدراسة الحالية، وتتمثل المفاهيم الأولية قبل العددية في الآتي:

ع - I- ا - مفهوم التصنيف. 
هو القدرة على تجميع الأشياء التي لها نفس الخصائص، وقد يتم وفقا لبعد واحد مثل (الثكل، الحجم، اللون، النوع، الاستخدام، .. ) وقد يتم وفقا لبعدين معا وتعتبر مهارة التصنيف هي أولى المهارات التي يكتسبها الطفل، ويمكن الإفادة من ذلك بالنسبة لتعليم اللغة العربية لطفل الروضة في تقديم الخبرات التعليمية (المحتوى)، باستخدام الخر ائط الذهنية في تصنيف المفاهيم اللغوية المكتسبة و المتعلمة وفقًا لأبعاد متنو عة ومتعددة.

\section{ع ـr_r ـ مفهوم التسلسل.}

هو القدرة على ترتيب الأثياء بناء على خاصية معينة مثل (الحجم، اللون، الطول) في نطاق تصاعدي أو تنازلي، أي وضعها فى مجمو عة من الأول للأخير، ويمكن الإفادة من ذلك فى تعليم اللغة العربية للطفل في اكسابه المفردات الدالة على أسماء التفضيل (أكبر ، أصغر، أكثر) من خلال مواقف اتصالية، وتوظيف مفهوم التسلسل في أساليب التعزيز لاستجابات الأطفال فى الألعاب التعليمية التنافية القائمة على مبدأ التلعيب الذى يقوم على استخدام عناصر الألعاب (النقاط ـ المستوى الذى يصل إليه ــ الترتيب وسط المجموعة ـ الجوائز ـ الأوسمة التي يحصل عليها كلما حقق إنجازًا) في بيئات التعلم' .

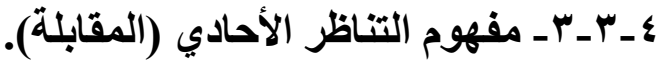

هو القدرة على مواعمة شيئين كل منهما للآخر؛ لأنهما ينتميان إلى نفس الفئة، مثل مقابلة المهن بالأدوات الخاصة بكل مهنة، أو عدد أطباق بعدد الأطفال، أو التشابه بين حروف الهجاء والمقاطع الصوتية فكل عنصر من المجموعة الأولى يقابلها عنصر و احد من المجموعة الثانية.

ودلت أبحاث بياجيه على أن الطفل لا يدرك مفهوم التناظر إدر اكا كاملا إلا بعد سن السابعة، فى حين أن التجارب المشابهة فى البيئة المصرية أثبتت أن الطفل بدرك مفهوم العدد عند سن الخامسة، وقد تم إرجاع ذلك الاختلاف إلى عناصر الموقف التجريبي، واختلاف البيئة واختلاف العينة، واختلاف أدوات التجربة، و التي استخدمت فيها التجربة المصرية خمس كرات مقابل خمس دميات، بينما استخدم بياجيه ستة أكواب مقابل ستة زجاجات فارغة، فقد تكون ألفة الأطفال بالكرات والدمي وشغفهم بها هو الذى

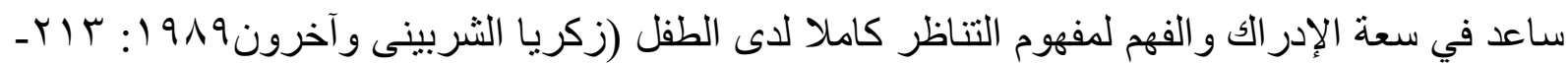

- gamification in Education (2016). Retrieved from : http:// www.learning-theories.com/gamification-in-education.html -https://www.mocaf.gov.ae/docs/default-source/default-document-library/gamification_ar.pdf?sfvrsn=0 ـ تامر الملاح ونور الهدى فهيم (7 ( • (Y): الألعاب التعليمية الرقمية والتنافسية، دار السحاب للنشر، القاهرة. 
استخلصت الباحثة من هذه التجربة أن المفاهيم اللغوية التي قد يصعب على طفل الروضة استبعابها

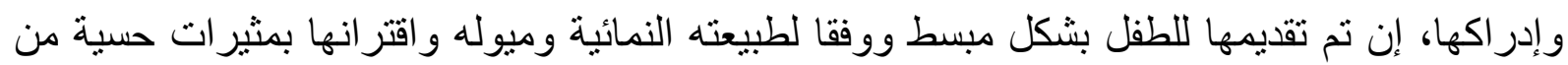
بيئته تثثر شغفه للتعلم، و الاكتثاف فإن ذلك يبسط المفاهيم ويساعد في إدر الك معاني الأشياء المر اد تعلمها،

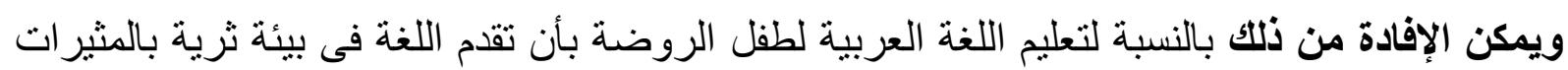
المحببة لنفس الطفل ولعالمه وهو عالم اللعب والتمثيل وأن تقدم عبر مواقف اتصالية حياتية مرتبطة بالخبر ات السابقة له.

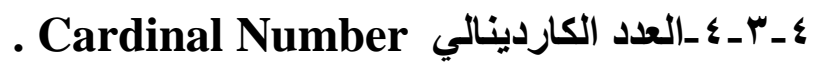

هو العدد الذي نجيب به على سؤال كم عنصر ا بالمجموعة ويعرف بالعدد الكمي، ويتعامل الطفل هنا مع ما يسمى بسعة العدد مثل (خمس بالونات، بنتان،...) كما يستطيع الطفل أن يعد إلى الثلاثين وحتى المائة،

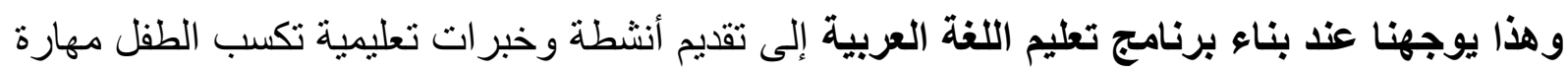
العد وتعلم الأعداد باللغة العربية حسابيا ولغويا واستخدامها في المو اقف الاتصالية.

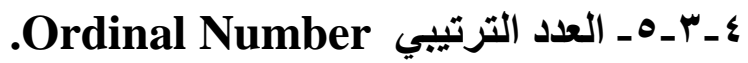

هنا يستخدم العدد ليدل فقط على ترتيب العناصر فرقم المنزل (1) ورقم المنزل (آ) هذا لا يعنى أن

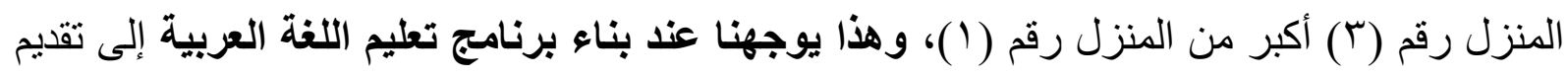

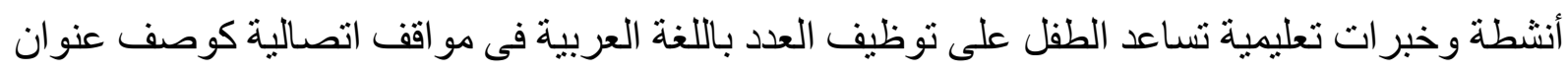
مكان ما أو أرقام عربات القطار أو أرقام كر اسي الطائرة .

\section{צ_-r_r - العدد القياسي Measuring Number.}

هنا يستخدم العدد كدالة لقياس كمية ما، كأن نقول خمسة أكواب، عشرة جنيهات، سبعة أمتار، وهذا

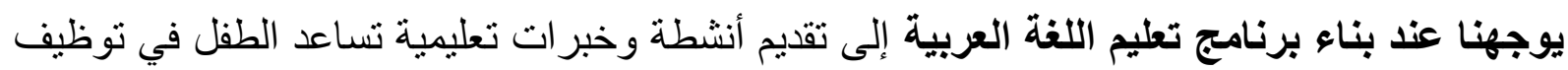
العدد باللغة العربية فى مو اقف اتصالية كمو اقف البيع والثراء، و استخدام العملة.

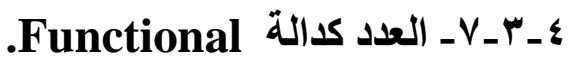

لا يقصد باستخدام الأرقام هنا عد الأشياء أو ترتيبها، أو معرفة كميتها ولكن يستخدم للالالة على شيء ما

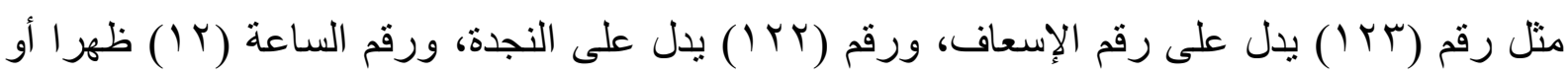

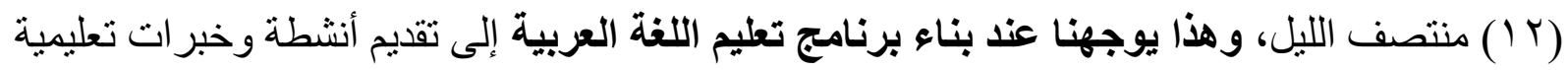
تكسب الطفل القدرة على توظيف الأعداد في مختلف المواقف الحياتية الاتصالية، مثل (تعليم الساعة،

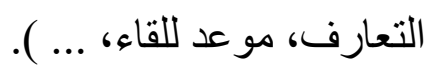


هي المجموعات التي تحتوى على نفس العدد من العناصر و لا علاقة لها بنوعية العناصر أو ترتيبها مثل

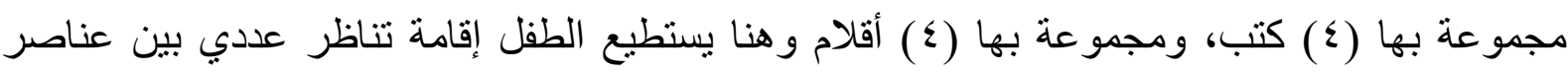

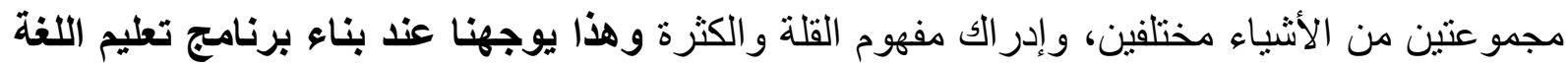
العربية إلى تقديم أنثطة وخبرات تعليمية تكسب الطفل العديد من المفردات اللغوية (أكبر من، و يساوي، و أصغر من) وتنمي مهار ات التفكير وحل المشكلات والاستتناج و المقارنة و غير ها من العمليات العقلية

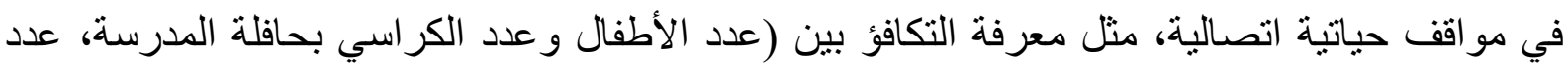
قطع الحلوى و عدد الأصدقاء، .. ) على أن يستخدم الطفل اللغة العربية في التواصل و التعبير عن ذلك.

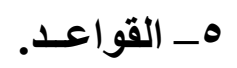

تتعلق القو اعد أو الأحكام بالمفاهيم؛ فهي أحكام تصدر بشأن هذه المفاهيم و علاقتها مع بعضها البعض مثل (الثتاء بارد، النار تحرق) ويختلف نمو القو اعد وتكوينها لاى الطفل باختلاف مر احل النمو.

فى ضوء ذللك يجب أن يراعى فى بناء برامج تعليم اللغة العربية طبيعة الأحكام التي تصدر عن الطفل في هذه المرحلة العمرية، وإعداد مواقف اتصالية بستطيع الطفل من خلالها أن يستخدم اللغة العربية لإصدار قو اعد وأحكام حول الدفاهيم الموجودة في البيئة المحيطة به مثل (الأرنب سريع، الأسد حيوان مفترس، ..) و إكساب الطفل القدرة على توظيف الصفات التي تتناسب مع الموصوف و إدر الك الفرق بين

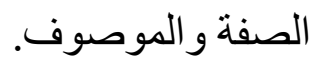

وحيث أن الوحدات المعرفية ليست ثابتة و إنما تخضع لعملية نطور مستمرة فى داخل النشاط المعرفي العام، و أنه لا يوجد حد فاصل بين الوحدات المعرفية والعمليات العقلية، فقد أكسب ذللك النمو العقلي طفل

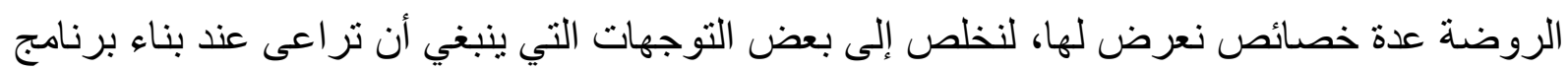
الدراسة المقتر ح لتعليم اللغة العربية وتتمثل هذه الخصائص فيما يلي:

\section{خ خصائص النمو العقلي لطقل الروضة.}

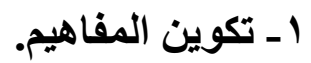

يتكون لاى الطفل العديد من المفاهيم مثل مفهوم المكان ومفهوم الزمن ومفهوم العدد وغير ها من مفاهيم المأكو لات و الملبوسات و الثخصيات وبالتدريج تنمو لديه المفاهيم والمعاني المجردة و التي تظهر بنسبة التهن

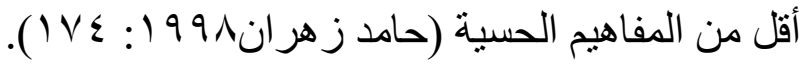


وهذا يوجهنا في بناء برامج تعليم اللغة العربية إلى تقديم المفاهيم الحسية أكثر من المفاهيم المجردة عن طريق الخبرات المتكررة مع الأشياء ،والأشخاص ،والأحداث ،و المواقف وربطها ببيئة الطفل وثقافة المجتمع الذى يعيش فيه حتى يتكون لدى الطفل العديد من المفاهيم التي تكون محتوى معظم النشاط العقلي، التي يستخدمها الطفل خلال المو اقف الاتصالية للتعبير عن احتياجاته والتواصل مع الآخرين من خلال اللغة.

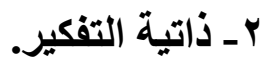

ينظر الطفل إلى الأمور والبيئة المحيطة به من خلال عالمه الخاص وبناء على مخططاته المعرفية، و قدر اته العقلية أي بما يعنيه الثيء بالنسبة للطفل وليس بما هو عليه فى الواقع، فالطفل يركز انتباهه أو تفكيره على مظهر أو بعد واحد للمشكلة أو للحدث أو الموقف ويغفل المظاهر الأخرى، فهو لا يسنطيع أن يستوعب أكثر من بعد واحد فقط من الموقف أو الحدث في كل مرة، فالطفل يدرك العالم من منظوره

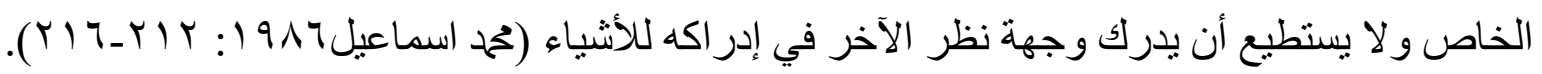
وهذا يوجهنا في بناء برامج تعليم اللغة العربية إلى ربط المحتوى التعليمي بمستوى إدراك الطفل وتفكيره وبناء أنشطة تعليمية تشجع على الحوار والمناقثة والتواصل بين المتعلمين على أن يتناول الموقف التعليمي بعدا واحدا يدور حوله مما بياعد في ثركيز انتباه الطفل من ناحية، والتأكد من فههه و استيعابهح لما يقدم لهم من معارف ومهار ات من ناحية أخرى.

\section{ب-الحسبية.}

يتحسن تفكير الطفل الحدسي من الر ابعة وحتى السابعة حيث يستطيع الطفل أن يخمن حل أي مشكلة ما أو إدر الك العلاقات بناء على ما يتخيله وتظهره له حواسه فهو، يعتمد بشكل كبير على حو اسه واستنتاجاته أكثر من أي شيء آخر، فإدر اكه للأشياء يكون عن طريق تأثثير ها الظاهر، ونتائجها المحسوسة، وليس ربطها بأسبابها الحقيقية، كما تتمو لدى الطفل القدرة على الاستتناج، و تكوين المفاهيم والتعميم بصورة بسيطة هي أقرب من تفكير الطفل الحدسي عن تفكيره المنطقي؛ فبدلا من استطاعته استكثاف العلاقات و المسبيات و النتائج، نجده قد يصل إلى العلاقات أو يعرفها دون القدرة على فهمها أو تفسيرها (محمد

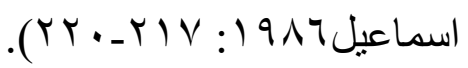

وهذا يوجهنا في بناء برامج تعليم اللغة العربية إلى أن تتضمن الخبرات التعليمية العديد من الأحاجى و الألغاز اللغوية والمعرفية؛ لاكتساب المعلومات و المهار ات اللازمة للطفل والتي تساعده في الوصول إلى المعلومات و المعارف بطريقة غير مباثرة تعمل على تنمية مهار ات تفكيره و قدر اته في التواصل، ورلا تعتمد على التلقين و الحفظ والاسترجاع لما تم تعلمه من قبل. 
ع ـ الإحيائية.

تعنى إعطاء الأشياء المادية صفة الحياة فنجد الطفل يضفى المشاعر والحياة على كل الأشياء الجامدة، و المتحركة كتعامله مع الدمية على أنها كائن حي أو إسقاط الثخصيات التي يحبها على أيّة أداةٍ ير اها، مثل

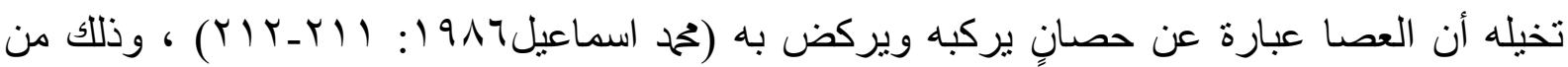
خلال اللعب الإيهامي كما تنمو قدرة الطفل على التخيل في هذه المرحلة بشكل سريع، فيجعله شغوفًا بالاستماع إلى القصص والأحداث التي تدور على ألسنة الحيوانات أو الشخصيات الكارتونية (خحم (90)

وهذا يوجهنا في بناء برامج تعليم اللغة العربية إلى إعداد المحتوى اللغوي التعليمي وتقديمه في صورة قصص هادفة ومواقف اتصالية بين الشخصيات المحبية للطفل، كتجسيد الحروف الهجائية مثلًا لتتفاعل وتتو اصل مع بعضها البعض ومع الطفل خلال الموقف التعليمي واستخدام الوسائل التعليمية والأدوات تيسر على المتعلمين تحقيق ذلك.

هـ القدرة على التزكر والتركيز.

تزداد قدرة الطفل على التذكر في مرحلة ما قبل المدرسة بشكل ملحوظ لتصل الذاكرة في هذه المرحلة إلى ما أسماه الباحثون "العنصر الذهبي للذاكرة" وخاصة الذاكرة السمعية والبصرية للطفل، فنجده يتذكر الكلمات والعبار ات المفهومة أيسر من تذكر الكلمات والعبار ات الغامضة، وبزيادة القدرة على التذكر، تنمو القدرة على الحفظ، وترديد الأغاني والجمل والعبار ات وغير ها، كما تزداد طول فترة التركيز فى

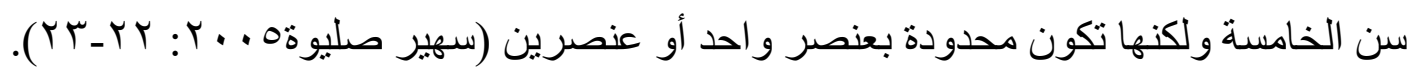

وهذا يوجها في بناء برامج تعليم اللغة العربية إلى عرض المعلومات لفظيا وبصريا وتضمين الخبرات التعليمية مجمو عة متنوعة من آيات القرآن الكريم والأحاديث الثريفة والأدعية والأناثيد السهلة ويسيرة الفهم للطفل والتي يمكن توظيفها لاكتساب الطفل من خلالها العديد من المهارات اللغوية و المعارف و المعلومات ضمن برنامج الدر اسة.

7ـ - القدرة على التعلم.

تتمو قدرة الطفل على التعلم من الخبرة والمحاولة، والخطأ، مما يجعل الطفل فى حالة نشاط عقلي دائم لمحاولة كشف العالم من حوله (حامد زهر ان 9191 ( : 1 ) ). 
وهذا يوجهنا في بناء برامج تعليم اللغة العربية إلى إعداد أنشطة تعليمية تربط بين الخبرات السابقة و الخبرات الجديدة مع تكرار التدريب والمران للتغلب على أي قصور يواجه المتعلمين و إعداد مواقف تعليمية تزيد من دافعيتهم للتعلم و الاكتشاف.

\section{• الأسس والتوجهات المستخلصة من المحاور السابقة:}

من خلال عرض طبيعة النمو العقلي المعرفي لطفل الروضة، مر احله والخصائص المعرفية العقلية للطفل ودر استهم وتحليلهم، استطاعت الباحثة أن تخلص إلى الأسس والتوجهات التي يمكن أن يستتد إليها عند بناء برامج تعليم اللغة العربية لطفل الروضة وتتمثل هذه التوجهات فيما يلي:

ا ـ تنظيم المادة اللغوية تنظيما متسلسلا تسلسلا سيكولوجيا: من الكل إلى الجزء، ومن المعلوم إلى المجهول، ومن السهل إلى الصعب، ومن المحسوس إلى المجرد، وفقا لتدرج النمو المفاهيمي لدى الأطفال. זـ استخدام الوسائل التوضيحية المتنوعة مثل: (الصور الملونة، و النماذج المجسمة، و الكتب التفاعلية، و المسجلات الصوتية، والأفلام والعروض الإيضاحية و ...)، في تعليم مفردات جديدة للطفل عن محصوله اللغوي ؛لما لها من أهمية في توضيح وتكوين الصورة الذهنية للأشياء و المحسوسات. بـ استخدام أساليب التعلم النشط في تقديم مادة لغوية تقوم على النشاط التخيلي الرمزي للطفل للتواصل باللغة مثل: (لعب الأدوار - التمثيل - الألعاب اللغوية ـ الخرائط الذهنية - الحوار

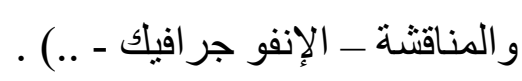

عـ بناء أنشطة تستند على التعلم الفردي و الثنائي والجماعي والتي تتطلب من الطفل المشاركة

$$
\text { الإيجابية و التفاعل في المو اقف التعليمية أو الخبر ات الجديدة. }
$$

هـ تقديم المفاهيم الحسية أكثر من المفاهيم المجردة وربطها ببيئة الطفل وثقافة المجتمع الذى يعيش فيه للتعبير عن احتياجاته و التو اصل مع الآخرين من خلال اللغة. جـ تضمين المحتوى التعليمي العديد من الأحاجى والألغاز اللغوية والمعرفية التي تسهم في تتمية المهار ات العقلية لدى الطفل مثل ( التذكر - التفكير - التخيل ـ التحليل ـ المقارنة ـ الاستنتاج - ..) وتساعده في اكتشاف المعرفة بنفسه و اكتسابها مما يدفعه للتفكير باللغة العربية و إنتاجها في مواقف اتصالية. 
Vـ عرض المعلومات لفظيا وبصريا وتقديم أنشطة تراعى الفروق الفردية بين الأطفال في طبيعة التعلم واكتساب المعرفة وهذا يقتضى أن نقمها في أثكال مختلفة فقد تكون سمعية أو مرئية أو محسوسة وملموسة. ^ـ بناء أنثطة لتعليم الطفل ظرف الزمان وظرف المكان من خلال اكسابه مفهوم المكان (المنزل -

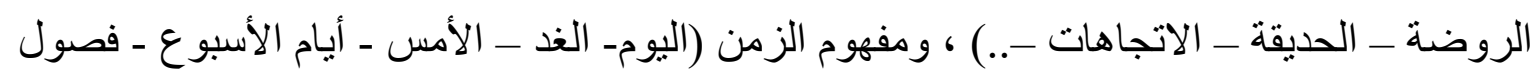

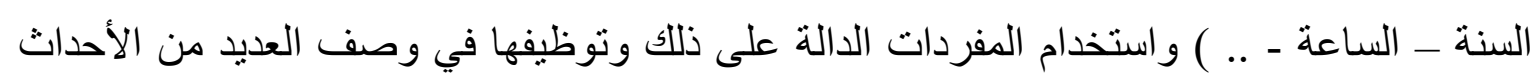
المرتبطة بأماكن متنو عة و في تسلسل زمني وفقا للموقف الاتصالي. وـ تصميم مو اقف تعليمية اتصالية تكسب الطفل مفهوم العدد ومهارة العد باللغة العربية حسابيا ولغويا

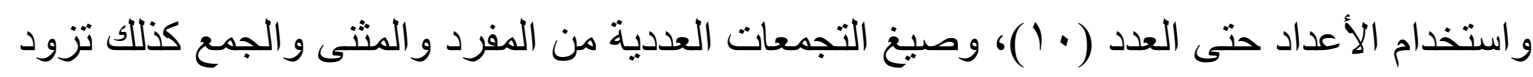

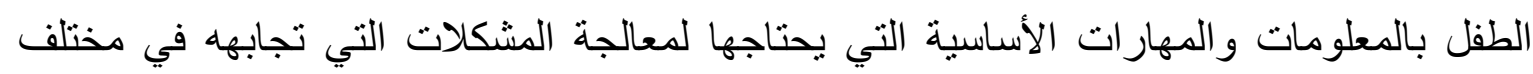

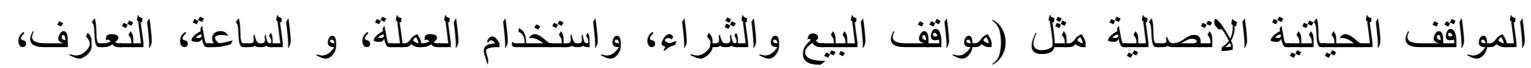

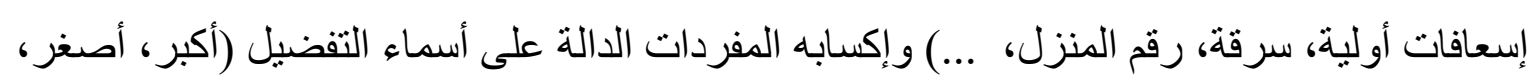
أكثر) وتوظيف مفهوم التسلسل في الموقف التعليمي.

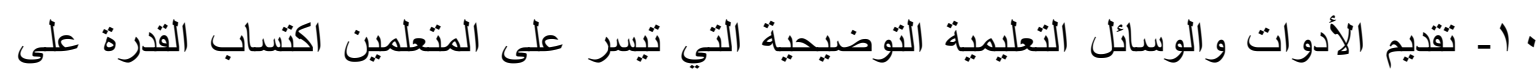

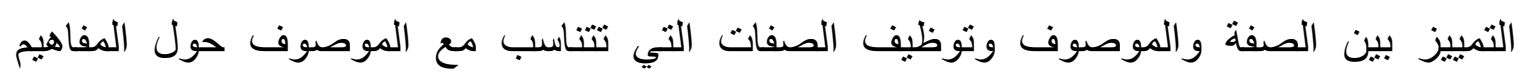
الموجودة في البيئة المحيطة بهم، مثل (الأرنب سريع، الثمس ساطعة، الثار عز مزدحم، ...). 11 - ربط المحتوى التعليمي ببعض من الآيات القرآنية، وبعض من الأحاديث الثريفة والأدعية

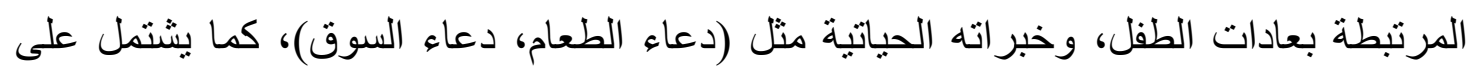
بعض الأناثيد و المفاهيم الغنائية و الحكايات الثعرية الهادفة.

r إــ إعداد أنشطة تعليمية تربط بين الخبر ات السابقة والخبرات الجديدة مع تكرار التدريب و المران للتغلب على أي قصور يو اجه المتعلمين وإعداد مو اقف تعليمية تزيد من دافعيتهم للتعلم و الاكتشاف. با 1 ـ إعداد بيئة تعلم ثرية بالمثير ات المحبية لنفس الطفل ولعالمه وهو عالم اللعب وتقديم أنشطة تستند على التعلم الفردي والثنائي والجماعي و التي تتطلب من الطفل المشاركة الإيجابية والتفاعل في المو اقف التعليمية أو الخبرات الجديدة.

§ اـــاستخدام أساليب التعزيز المختلفة لاستجابات الأطفال وإسهاماتهم و إنجازاتهم الفردية

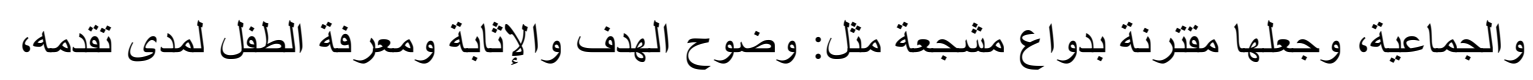

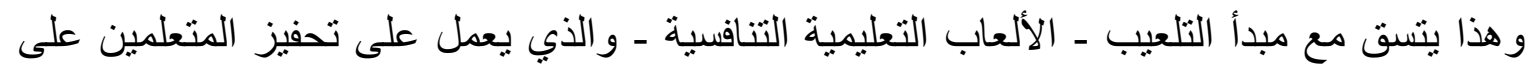


التعلم باستخدام عناصر الألعاب، وهي ( النقاط - المستوى الذى يصل إليه - الترتيب وسط المجموعة ـ الجوائز و الهدايا ـ الأوسمة التي بحصل عليها كلما حقق إنجازًا) في بيئات التعلم، وهو ما يتو افق مع طبيعة الطفل النمائية في هذه المرحلة وميله للعب و الاكتشاف و الإنجاز . r- النمـو اللغـوي لطقل الروضــة.

يقصد بالنمو اللغوي قدرة الطفل على فه كلمات جديدة لم تكن ضمن حصبلته اللغوية و امتلاكه القدرة على استعمالها في مواقف جديدة، كما يعرف النمو اللغوي بأنه عملية اكتساب الطفل للكلام، وحدوث تطور في لغة الطفل، متمثلة فى زيادة عدد المفردات، والقدرة على إدرالك المعاني، وإنتاج كلمات ومفردات جديدة على قاموس الطفل، و القدرة على استعمالها في التو اصل اللغوي مع الآخرين.

ويقاس النمو اللغوي لدى الطفل بعدد المفردات المكتسبة ونوعها، وطول الجملة التي ينتجها الطفل،

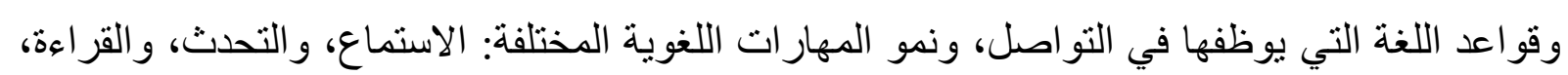

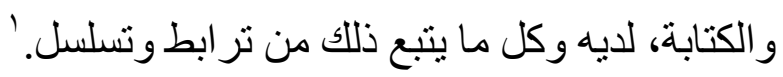

\section{• مراحل النمو اللغوي لطقل الروضة.}

وبدر اسة نتائج الدر استات المختلفة التي حددت مر احل النمو اللغوي خلال فترة ما قبل المدرسة، نجد أن

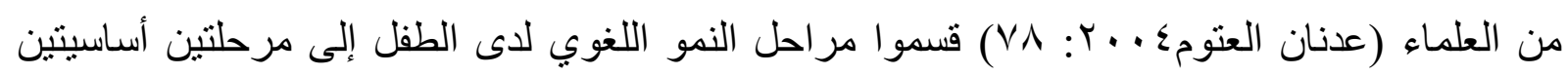
os

\section{ا ـ مرحلة ما قبل اللغة. Pre-Linguistics Stage}

و يطلق عليها البعض مرحلة الأصوات غير اللغوية، وتبدأ من الميلاد حتى العام الأول.

Y L المـرحلة اللغــوية. Linguistics Stage

أو كما يطلق عليها العديد من الباحثين مرحلة الكلام الحقيقي وفهم اللغة، وتعتبر هذه المرحلة هي أساس تعلم الطفل الكلام الحقيقي، واستخدام اللغة، وتبدأ من السنة الثانية حتى بلوغ الطفل سن السادسة.

$$
\begin{aligned}
& \text { و تشتمل على عدة مراحل فرعية هي: } \\
& \text { ץ ـ ـ ـ مرحلة الكلام البرقي (في غضون السنة الثانية). } \\
& \text { r_r - مرحلة الأكثر من كلمتين (تمتد من Y - r سنوات) . }
\end{aligned}
$$

'انظر كلا من:

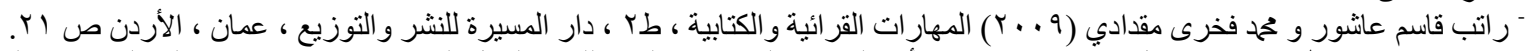

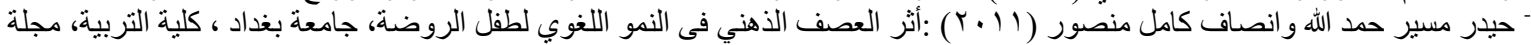

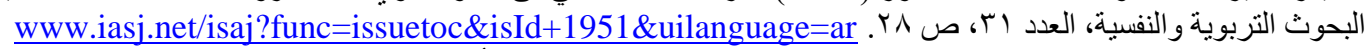

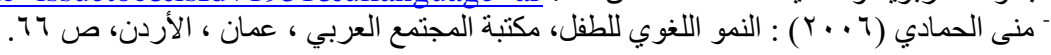


r Y r - مرحلة الجملة المركبة (تمتد من r - ع سنوات) .

$$
\text { ץ__ ـ مرحلة تطور المهار ات و المكتسبات اللغوية (تمتد من ع - } 7 \text { سنوات ).' }
$$

وبدر اسة هذه المراحل وفحصها توصلت الباحثة إلى أن المرحلتين (الجملة المركبة ـ تطور المهارات والمكتسبات اللغوية) تناسبان الخصائص النمائية لأطفال الروضة؛ لذا ستقتصر الدراسة الحالية على هاتين المرحلتين من مر احل النمو اللغوي، وفيما يلي عرض لهما:

\section{خ مرحلة الجملة المركبة}

و هي أن الطفل من ثناث إلى أربع سنوات يبدأ فى استخدام الجملة المركبة ، ويمر التعبير اللغوي بمرحلتين هما :

- مرحلة الجمل القصيرة: وتبدأ من العام الثالث، وتكون الجمل مفيدة، وبسيطة، وتتكون من ب - ع كلمات، وتكون سليمة من الناحية الوظيفية أي أنها تؤدي المعنى رغم أنها غير صحيحة من ناحية

$$
\text { التركيب اللغوي . }
$$

ـ - مرحلة الجملة الكاملة: وتبدأ من العام الرابع، وتتكون الجمل من ع ـ 7 كلمات، وتتميز بأنها

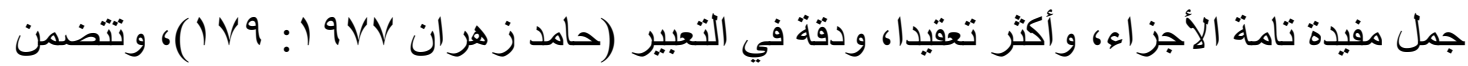
استخدام حروف الجر، و الضمائر، وصيغ الملكية، وأدوات الاستفهام، ويغدو الطفل في هذه المرحلة قادرًا على استخدام قو اعد الصرف حسب جنس المتكلم أو المخاطب، أو الغائب ذكرًا أو أنتى، وكذللك عدده مفردًا، ومثنى، جمعًا، وزمن الفعل ماضٍ، حاضر ، مستقبل، مما يشير إلى نمو

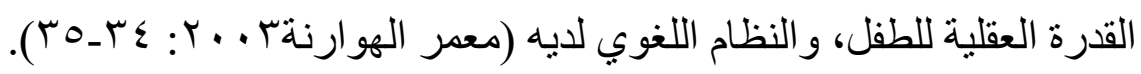

\section{خ مرحلة تطور المهارات والمكتسبات اللغوية.}

وتبدأ من عمر أربع سنوات إلى ست، وهي مرحلة رياض الأطفال، وتتطور المهار ات و المكتسبات اللغوية بعد ظهور الكلمات الأولى التي يستخدمها الطفل فى المواقف المختلفة المناسبة للكلمات، ويحدث نوع من التطور في مختلف المهارات اللغوية، ويكون الطفل قد اكتسب العديد من العناصر اللغوية، وتستمر المفردات، والأبنية الخاصة بتراكيب الكلام فى الازدياد، والتنوع، والعمق (أنسى قاسم199 إ:

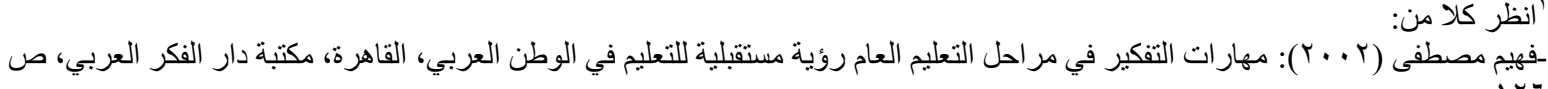

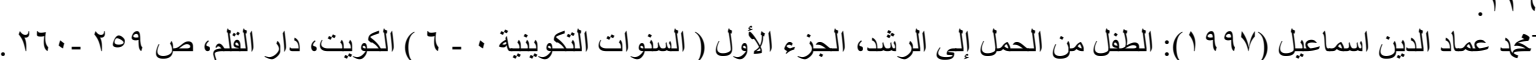




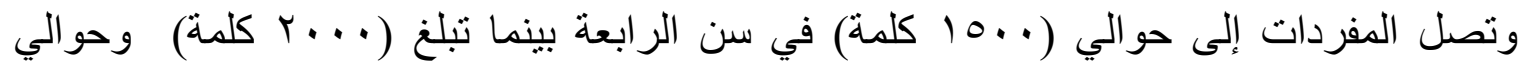

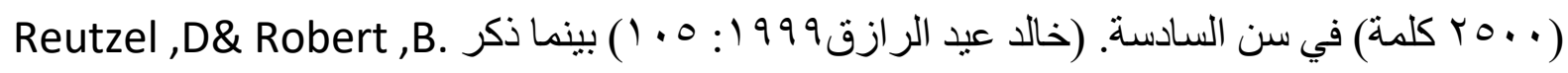

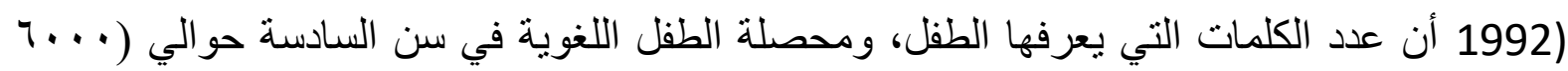

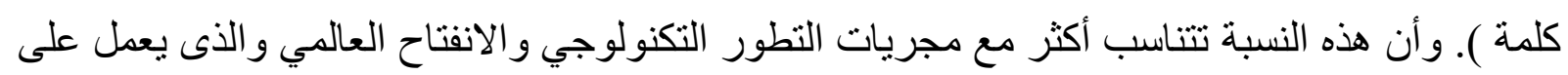

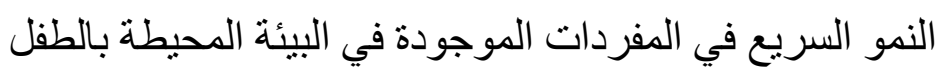
و هذا يوجهنا في بناء برامج تعليم اللغة العربية إلى ضرورة مراعاة اختبار المحتوى اللغوي كما وكيفا و المفردات المقدمة للطفل وربطها بثقافة المجتمع وبيئته، وتتاسبها مع الحياة العصرية و التكنولوجية التي لئي يعيشها الطفل من حوله.

كما يتحدد النمو اللغوي لطفل الروضة في زيادة قدر اته الاستماعية، والكلامية، حيث يبدأ الطفل استخدامه

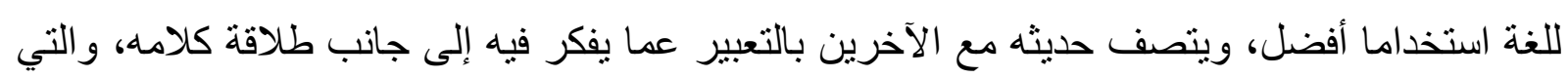

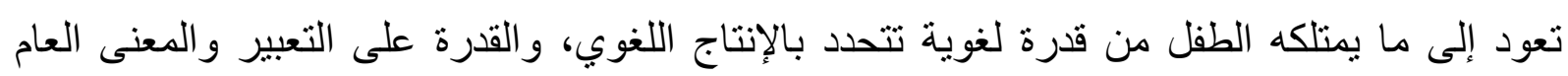
للحديث، وتركيب الجملة، ومعنى الكلمة، كل ذلك يمكن الطفل من صباغة أفكاره صياغة لغوية لغية صحيحة

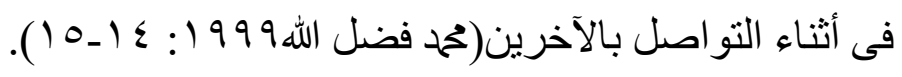

و هذا يوجهنا في بناء برامج تعليم اللغة العربية إلى تقديم الخبرات التعليمية بشكل رئيسي من خلال تنمية

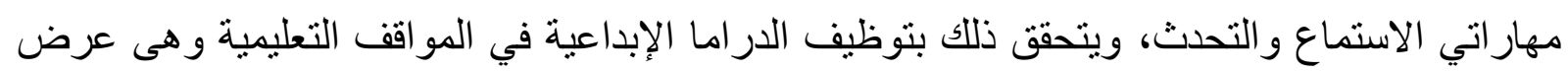
ارتجالي يقدمه الأطفال لتوظيف اللغة ، وينتج الارتجال من قدرة الطفل الإبداعية على خلق الثخصيات

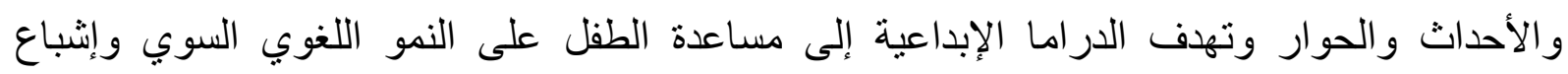
احتياجاته النفسية والاجتماعية، كما تخضع للملاحظة والتقنين من قبل المعلمين لإرشاد الطفل عن كيفية

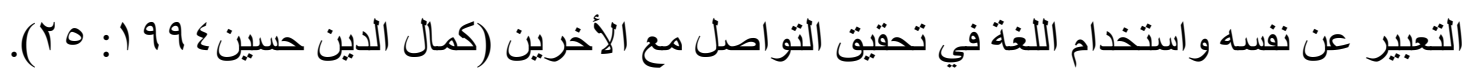

و المحصول اللغوى عند الطفل في هذه المرحلة ـ تطور المهارات والمكتسبات اللغوية ـ قد يكون

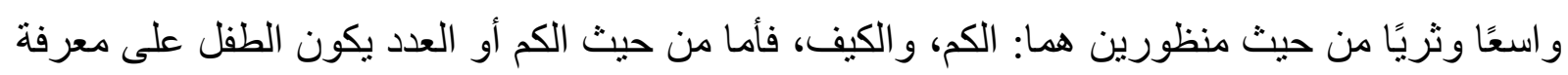

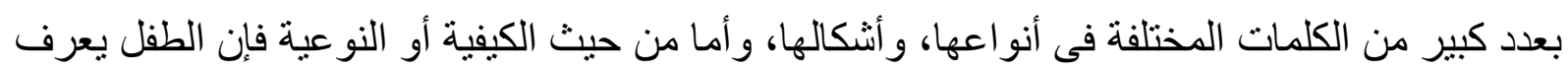

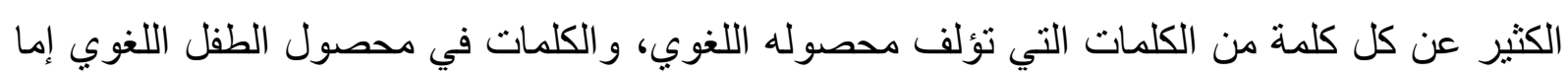

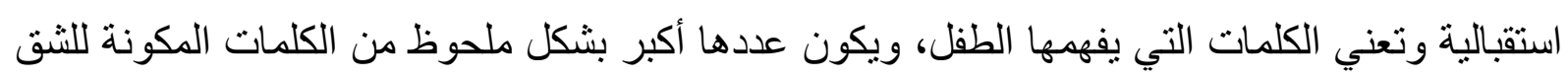
الثاني من محصوله اللغوي وهي الكلمات التعبيرية والتي تتمثل في عدد الكلمات التي يستخدمها الطفل عند الكلام. 
و هذا يوجهنا في بناء برامج تعليم اللغة العربية إلى تصميم أنشطة تعليمة لتنمية حصيلة الطفل اللغوية

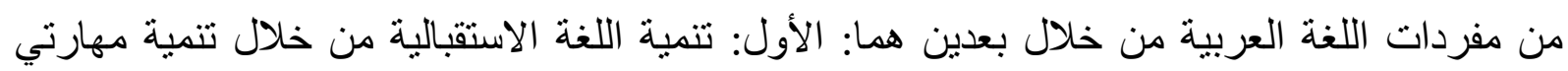

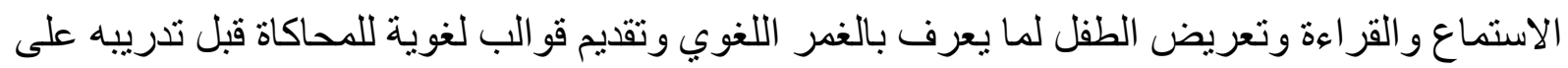

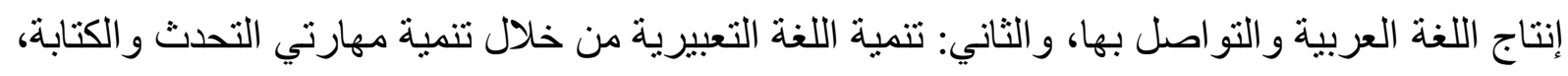
ولتدريب الطفل على إنتاج اللغة لا بد أن نولد فى عقل الطفل شعور ا بالجملة، وبنائها، وأن نقوم بمساعدنه

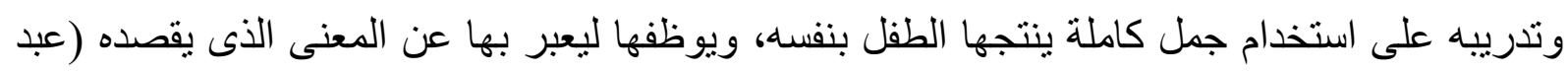

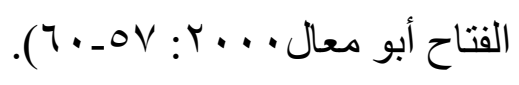

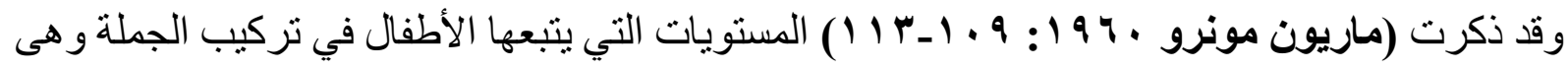
كالآتي:

- - المستوى الأول: الكلمات المنفصلة ويربطها الطفل بواو العطف. - - المستوى الثناني: جمل بسيطة بها فعل وفاعل، ويمكن الربط بينهما بواو العطف.

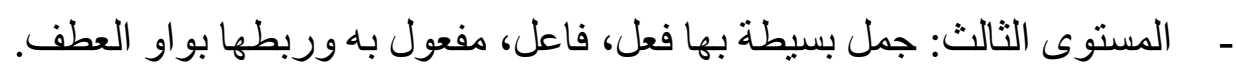
- - المستوى الرابع: جمل معطوفة بها حرف عطف غير الواو وتكون الجمل فقرة. - - المستوى الخامس: جمل مركبة تحوي أكثر من فقرة تابعة لفقرة أصلية.

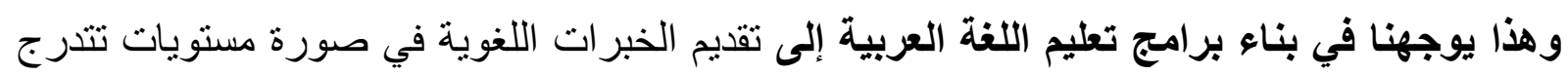
من الأسهل للأصعب، ومن الجزء للكل بداية من كلمات مفردة منفصلة أو مقطع واحد أو جملة بسيطة

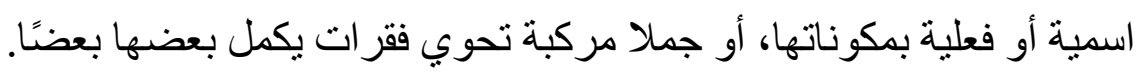

و لا يظهر النمو اللغوي للطفل في هذه المرحلة في القدرة على إنتاج جمل تامة مفيدة فقط، بل تتعدد مظاهر النمو اللفوي لاى طفل الروضة في عدة مظاهر أهمها ما يلي:

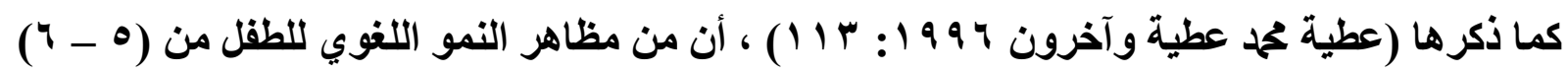
سنوات هي: - - ميتطيع أن يكتب بعض الكلمات و اسمه. - - يستطيع أن يدرك أنكال رسم الحروف في أول ووسط وآخر الكلمات. - - يستطيع أن يكتب الأعداد، وإجر اء العمليات الحسابية البسيطة. - القدرة على تحليل وتركيب الكلمات إلى حروفها الأصلية. - - مقة الكتابة، وضبط حجم الخط. ـ انتظام الكتابة على السطور في نهاية المرحلة. 


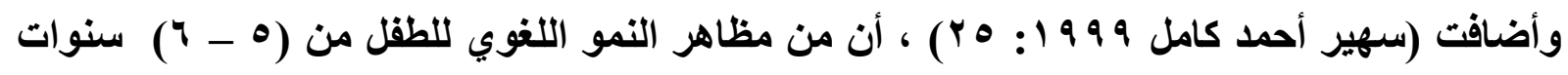
ـ يقلد الطفل بمهارة الأساليب المرتبطة بالكلام كأساليب الإخبار ، و النفي، و التعجب، والسؤال. ـ يعتمد الطفل للغة فى هذه المرحلة اعتمادًا رئيسيًا على الكلمة المسمو عة أكثر من المكتوبة.

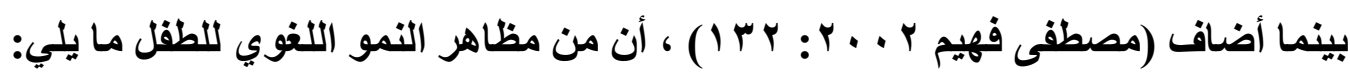

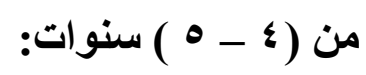
- يستطيع استخدام كثير من الأفعال و الصفات و الظروف وحروف الجر و الضمائر.

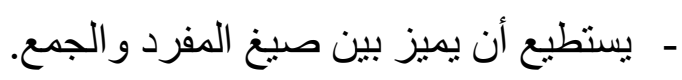
- - يعرف أسماء الإشارة (هذا - هذه). - يستطيع استخدام ضمير المتكلم (أنا ـ نحن)، وضمير المخاطب (أنت ـ أنتم)، وضمير الغائب (هو -

$$
\text { - هينطيع استخدام أدوات الاستفهام (متى - كيف - هل - كم - أين - لماذا). }
$$

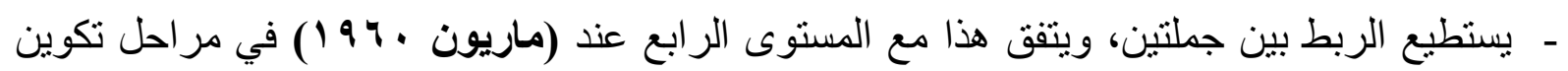

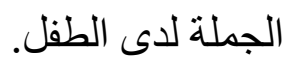
- يسمي كثير ا من الأشياء و الكائنات من خلال الصور.

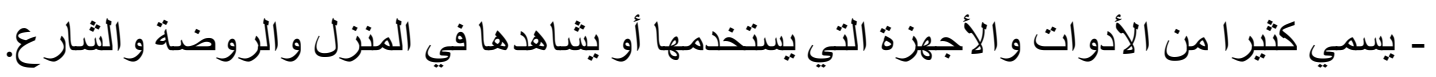
- يعرف أسماء الألوان الثنائعة.

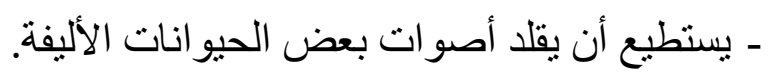
- يستطيع حفظ أغاني الأطفال و الأناتشيد.

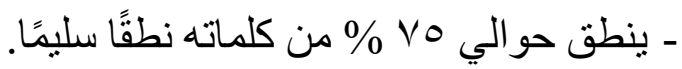

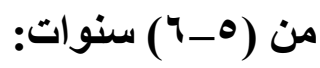
- يحسن الاستماع ( الإصغاء) إلى الآخرين. - يعرف صفات الأثياء، كاللون و الحجم و الثكل. - يستخدم الكلمات الوصفية تلقائيًا للأشياء، والكائنات، ( كبير - صغير ولئير - ناعم - خشن - مريض -

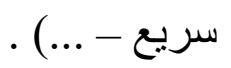
- يستطيع استخدام صيغ التذكير و التأنيث لبعض المسميات للإنسان و الحيو ان و الطيور. - يستطيع أن يتحدث بجملة مكونة من ست كلمات. 
ـ يعرف صيخ المفرد والمثنى والجمع، وضمير المتكلم، وضمير المخاطب، وضمير الغائب، والأفعال

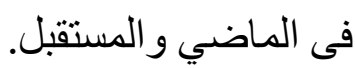
- يستطيع أن يسلسل أحداث قصة سمعها أو شاهدها من خلال الصور ، كما تتسم أحاديثه بالترابط إلى حد

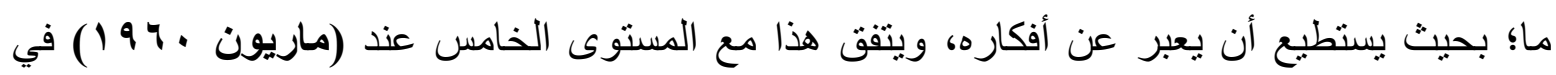
مر احل تكوين الجملة لاى الطفل. - يدرك تفاصيل الصور بكتب الأطفال المصورة. - يعرف متى يوظف كلمات (من فضلك - لو سمحت - شكرًا - آسف). - ينطق حو الي 10 \% من كلماته نطقًا سليمًا.

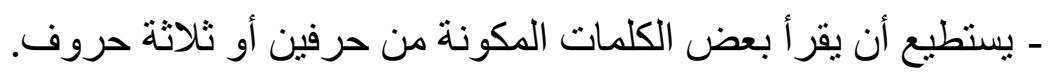

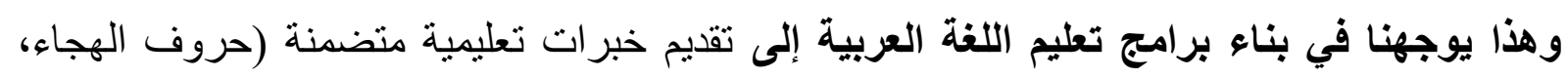

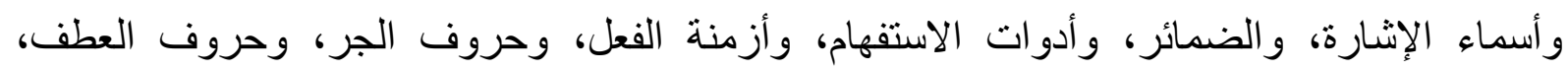

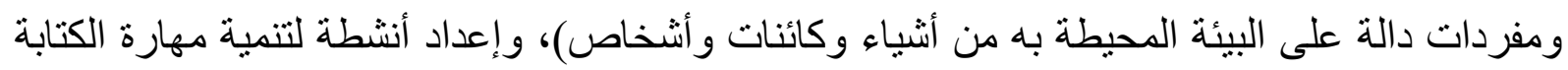

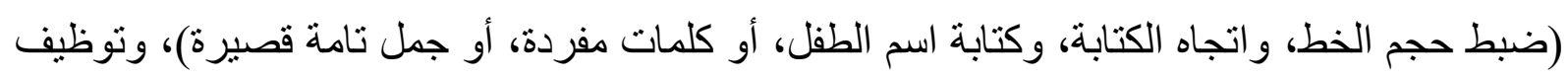

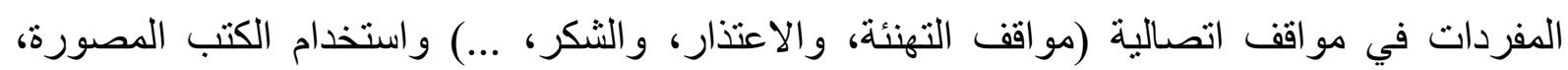
و الأغاني، و الأناثيد، و القصص الغنائية؛ لزيادة حصيلته اللغوية، و القدرة على التو اصل باللغة العربية.

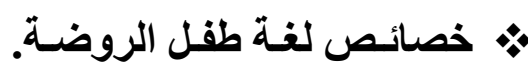

تأخذ لغة الطفل خصائص مميزة لها تحكمها طبيعة المرحلة النمائية، وما تتصف به من إمكانات تنمو وتتطور من خلال تلبية حاجات النمو لكل مرحلة، وما يتوافر في بيئة الطفل المحيطة به من مثير اتهات

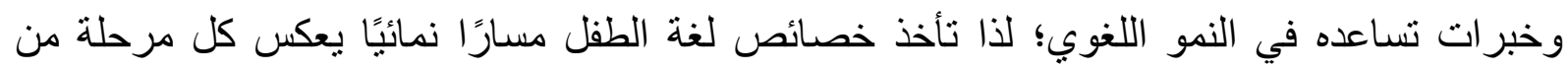
مر احل النمو اللغوي ومنطلباتها.

\section{وفيما يلي خصائص لغة طقل الروضة وما تتطلبه ليتعلم اللغة ويكتسبها.}

تناولت العديد من الدراسات اللغوية، والنفسية تحليل مظاهر النمو اللغوي للطفل وكذلك لغته، و التعرف على قاموسه اللغوي، وعلى مفاهيمه المختلفة، وعلى أكثر المفردات، و التراكيب الثنائعة فى ولى حديثه، والمعاني التي يعبر عنها حين يستعمل الكلمات ويوظفها، وخلصت إلى العديد من الخصائص وله

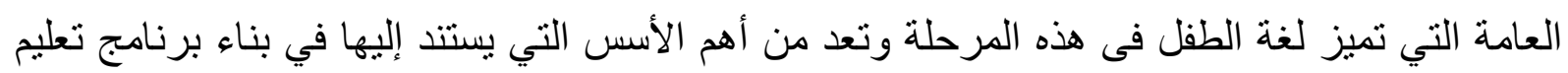

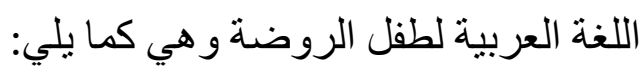




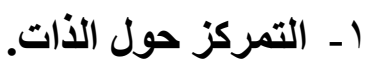

يغلب على الطفل التمركز حول الذات، ويعني أن يتحدث الأطفال دون أن يعنيهم أمر المستمع لهم من الكبار، فهم يتحدثون حتى لو لم بسمعهم أحد، و الطفل دائم الحديث حول نفسه لأن خبرته تكون محدودة، وكذلك تفكيره و إذا ما بدأ فى الاختلاط بغيره في سن الروضة لونة خفت النزعة الذاتية، ودخلت محلها النزعة

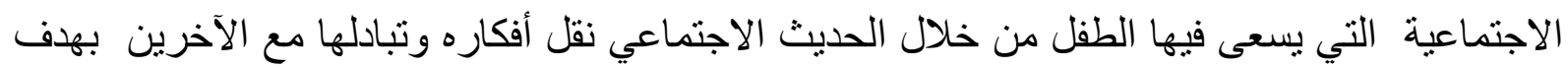

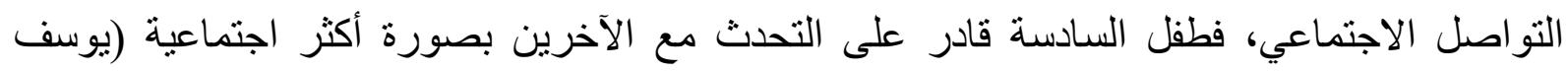

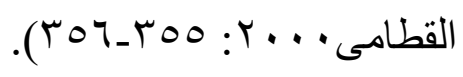

فى ضوء ذللك يجب أن يراعى فى بناء البرامج استخدام الأنشطة والتدريبات والألعاب اللغوية الفردية و الجماعية التي تتضمن الحديث عن الطفل ذاته و عن الطفل داخل بيئته وداخل المجتمع الأكبر.

\section{r- - بظلب على لغة الطقل إدراك المحسوسات.}

إن أغلب الكلمات التي يستخدمها الطفل فى مرحلة ما قبل المدرسة تدرك عن طريق الحواس؛ لأن الطفل أول ما يتعلم الكلام يبدأ بما تقع عليه حواسه، ويقع فى إدر اكه، و هذا يتفق مع النمو اللغوي للأطفال

وتكثر أسماء الذوات فى حصيلتهم اللغوية مثل (بابا - ماما - حليب - ...) ثم يتدرج في التعرف على الكلمات مثل (قطة - أرنب - بيت - ..) أما الصفات التي تصف الألوان، والأشكال، والأحجام، ..

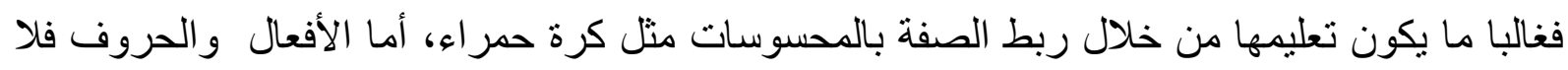

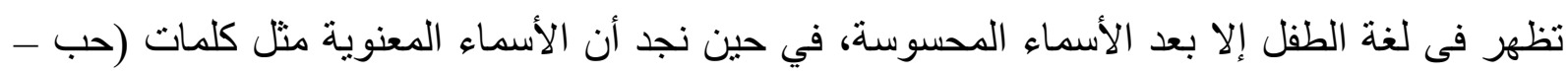

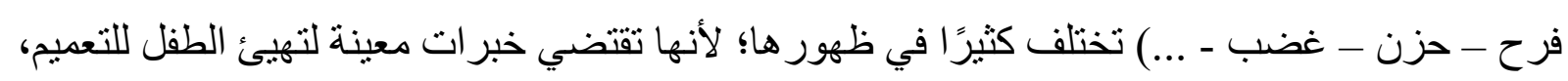

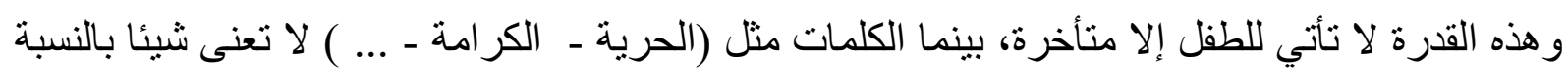
للطفل فى هذه المرحلة؛ لعدم ارتباطها بخبرات حسية لديه تمكنه من فهم معناها وتوظيفه في قاموسه

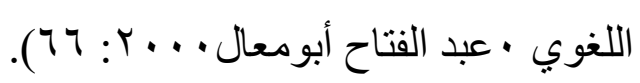

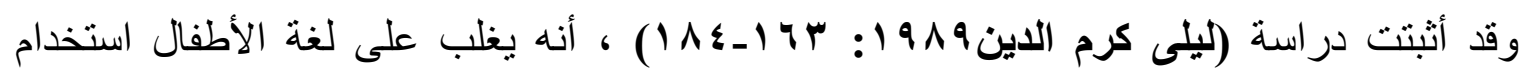

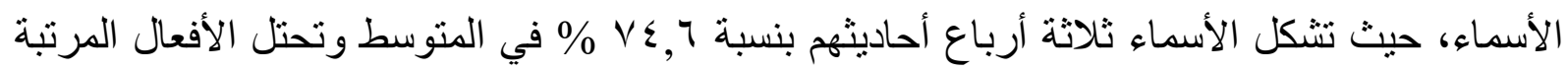

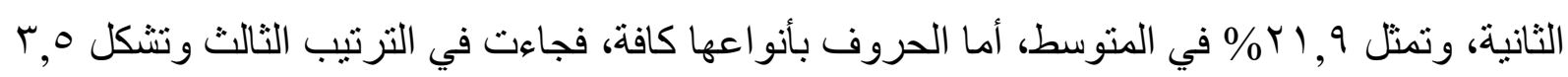

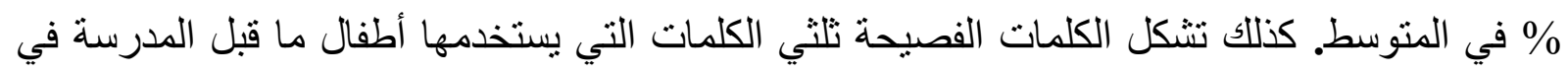
أحاديثهم حتى تبلغ نسبتها آ \% \% من مجموع الكلمات التي يستخدمها الأطفال. 
في ضوء ذلك يجب أن يراعى فى بناء البرامج نسبة شيوع أجز اء الكلام في حديث الطفل، و اكتسابه لها

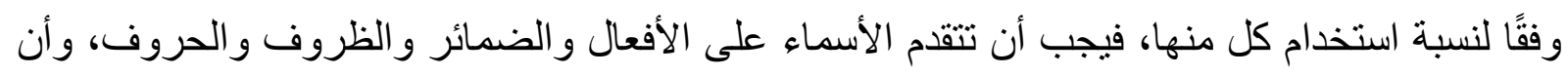
تقدم المفردة الثائعة في لغة الطفل على المفردة غير الثنائعة، وأن تقدم المفردات الحسية على المفردات المجردة.

\section{ب- تقديم المتحدث فى الجملة الخبرية.}

يبدأ الطفل فى عبار اته الخبرية بتقديم المسند إليه، ثم يذكر المسند بعد ذلك سواء كان اسمًا أو فعلًا، فيقول:

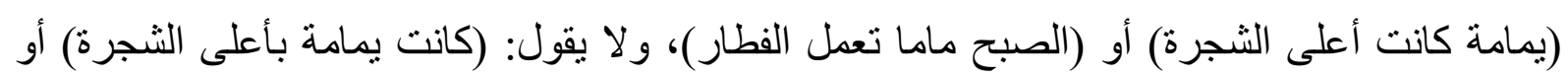

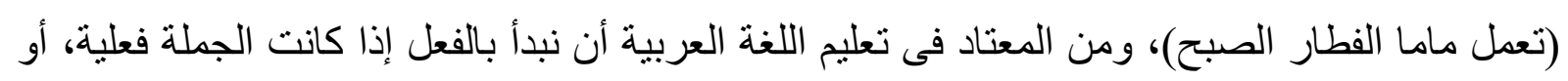

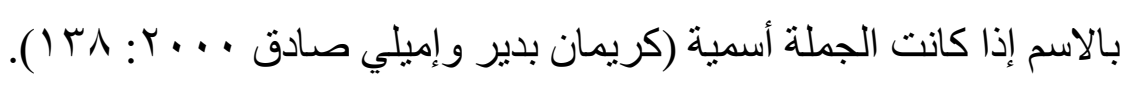
في ضوء ذللك يجب أن يراعى فى بناء البرامج أن يرد أي خطأ لأصله في اللغة العربية؛ لإكساب الطفل

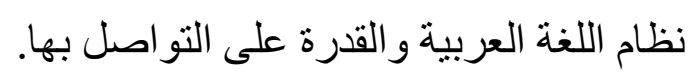

\section{ع ـ للطقل مفاهيمه وتر اكيبه الخاصة في الكلام.}

من المعروف أن اللغة ليست كلمات مفردة منفصلة، بل هي تر اكيب تؤدي معانٍ متكاملة، وكثير من

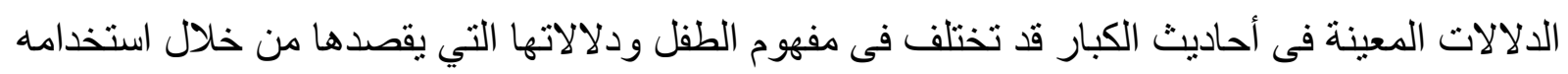

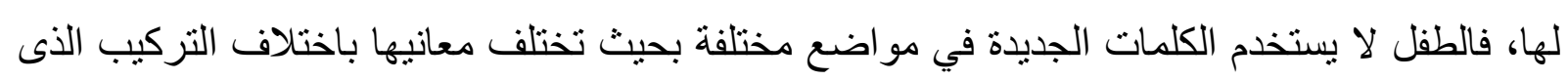

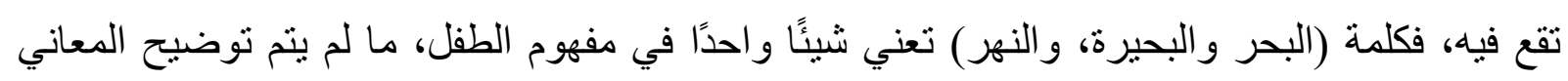

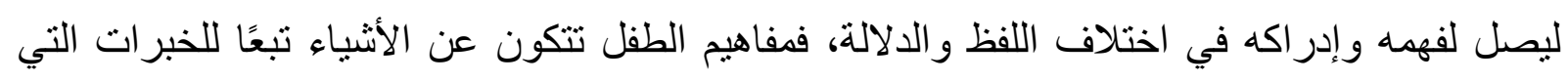

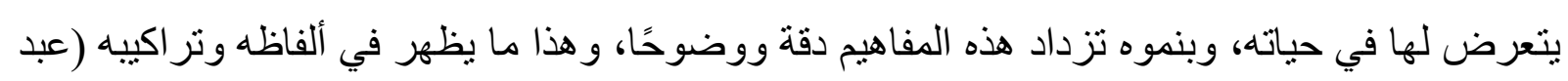

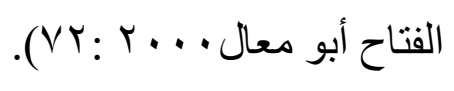

فى ضوء ذللك يجب أن يراعى فى بناء البرامج تقديم أنثطة نوضح الفرق بين المفردات المتقاربة في

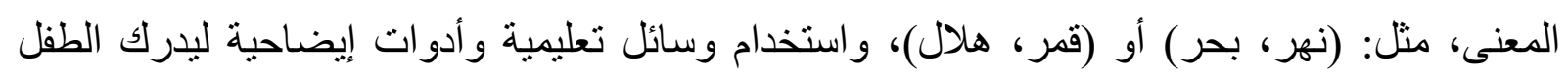

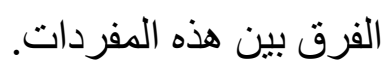

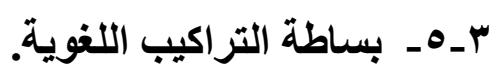

يغلب على لغة الطفل فى مرحلة ما قبل الددرسة بساطة التراكيب اللغوية، فتكون الجمل المستخدمة قصيرة واسمية وليس فيها شبه جملة، وأن درجة تركيز الطفل تتسم بالجزئية أي عدم قدرته على التركيز

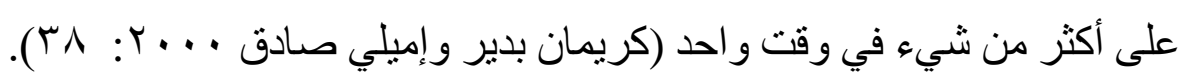


فى ضوء ذلك يجب أن يراعى فى بناء البرامج اختيار المفردات والتر اكيب اللغوية الثائعة و الواضحة بالنسبة للطفل.

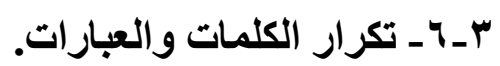

إن نكرار الثيء المألوف يعتبر نزعة طبيعية عند الطفل فهو يكرر ما اعتاد عليه من حركات، و أصو ات، وكلمات، ويعود ذللك لرغبته فى استخدام طاقاته العقلية والجسمية واستغلالها، فهو يعيد ويكرر وفي ذللك تأكيد على ذاته، وقد يكون التكرار فى كلمات الطفل هو تأكيد المعنى وإظهاره، مثل (أفضل أجري أجري بسرعة)، وتقل هذه الصفة تدريجيا كلما زادت خبراته، وزاد نموه العقلي، وبالتالي زاد محصوله اللغوي من الكلمات و التر اكيب والجمل و العبار ات(عبد الفتاح أبو معال . . . Y : (V). في ضوء ذلك يجب أن يراعى فى بناء البرامج تكر ار بعض الخبرات التعليمية والمفردات المر اد التأكيد عليها لاكتسابها، والتأكد من فهم واستيعاب الأطفال لها من ناحية، ومن ناحية أخرى لملاعمة الطبيعة اللغوية للطفل في هذه المرحلة ووجود الألفة في المحتوى اللغوي المقدم له.

\section{• الأسس والتوجهات المستخلصة من المحاور السابقة:}

من خلال عرض طبيعة النمو اللغوي لطفل الروضة ومراحله، ومظاهره، وخصائص لغة الطفل ودر استها وتحليلها، يمكننا أن نخلص إلى بعض الأسس والتوجهات التي يمكن أن يستند إليها عند بناء برنامج لتعليم اللفة العربية لطقل الروضة، وتتمثل هذه التوجهات فيما يلي:

اـ اختيار المفردات اللغوية البسيطة والثائعة المرتبطة بثقافة المجتمع وبالحياة العصرية

$$
\text { و التكنولوجية التي يعيشها الطفل حوله. }
$$

rـ توظيف الدر اما الإبداعية ولعب الأدوار في تنمية مهارتي الاستماع و التحدث. بـ إعداد أنشطة؛ لتنمية مهارة الكتابة (ضبط حجم الخط واتجاه الكتابة وكتابة اسم الطفل أو كلمات مفردة أو جمل تامة قصيرة)، وتوظيف المفردات في مواقف اتصالية (مواقف التهنئة، والاعتذار، و الثكر، ...) واستخدام الكتب المصورة والأغاني والأناثيد والقصص الغنائية؛ لزيادة حصيلة الطفل اللغوية والقدرة على التو اصل باللغة العربية. عـ بناء أنتطة تعليمية تقدم الخبر ات اللغوية فى صورة مستويات تتدرج من الأسهل للأصعب، ومن الجزء للكل بداية من كلمات مفردة منفصلة أو مقطع و احد أو جملة بسيطة اسمية أو فعلية. هـ أن يتضمن البرنامج أنواع الكلام (أسماء، أفعال، حروف، صفات) و الجملة الاسمية و الجملة الفعلية

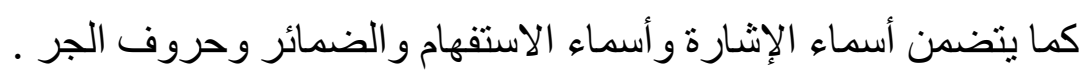


ــ أن يتضمن البرنامج أنواع الأسماء من حيث الجنس (مذكر - مؤنث)، ومن حيث العدد (المفرد -

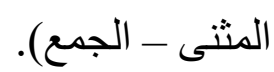

Vـ استخدام الأنشطة و التنريبات و الألعاب اللغوية الفردية و الجماعية وأن تتضمن الحديث عن الطفل

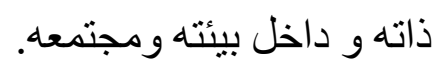
يـ تقديم المادة التعليمية وفقًا لنسبة شيوع أجز اء الكلام في لغة الطفل و هذا يقتضي تقديم الأسماء في

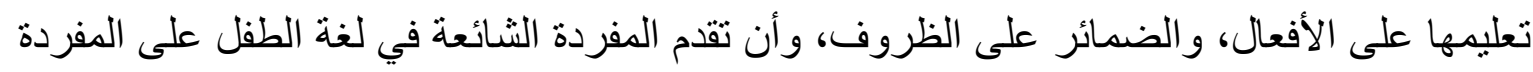

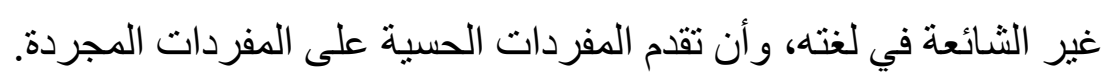
9 ـ رد أي خطأ لأصله في اللغة العربية لإكساب الطفل نظام اللغة العربية و القدرة على التو اصل بها.

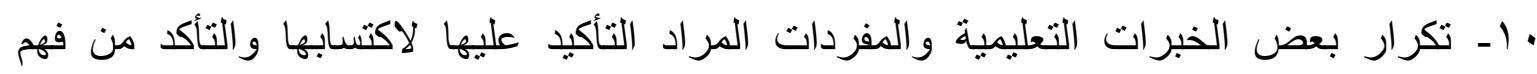
و استيعاب الأطفال لها من ناحية، ومن ناحية أخرى لملاءمة الطبيعة اللغوية للطفل في هذه المرحلة ووجود الألفة في المحتوى اللغوي المقدم لله.

1اـ التمهيد و التهيئة للخبرة الجديدة وتنشيط الخبرة السابقة واستدعاؤها وتطبيقها من خلال مو اقق اتصالية يمارس فيها الطفل اللغة العربية. r بـ بناء أنشطة تعليمية تكثف العلاقة بين الخبرات السابقة والخبرات الجديدة؛ لتحديد مواطن القصور و الضعف لدى المتعلمين وتزويدهم بأنثطة تدريبية أخرى متتوعة فردية أو جماعية.

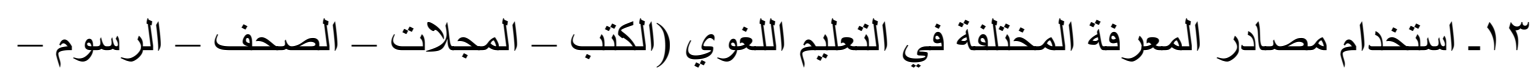

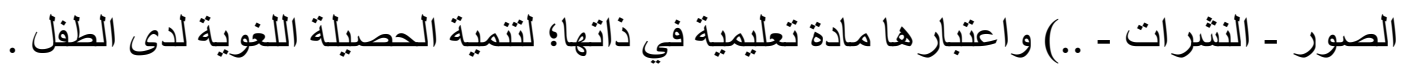




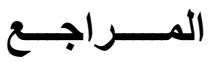

اـ أنسى محمد أحمد قاسم ( 1991 (1): مقدمة فى سيكولوجية اللغة، ج (، القاهرة ، مكتبة الأنجلو المصرية.

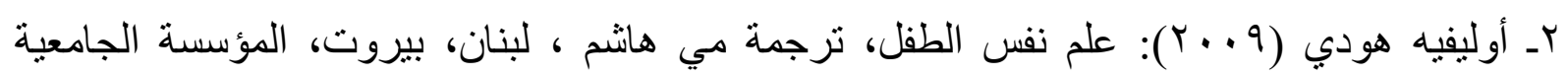
للار اسات و النشر. rـ إيمان نعمة كاظم (ب. ت) علاقة النمو اللغوي لأطفال الروضة بإتقان اللغة العربية الفصحى، الكلية التربوية المفتوحة، العراق، conference.org conference_research.alarabigh con 1704211417-1409058898=567.pdf.

عـ بطرس حافظ بطرس (^^ ㄷ): تنمية المفاهيم العلمية و الرياضية لطفل الروضة،الأردن، عمان، دار

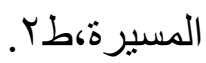
هـ تامر الملاح ونور الهدى فهيم (7 ( ب ): الألعاب التعليمية الرقمية والتنافسية،القاهرة، دار السحاب للنشر. جـ جميل الملائكة (911 (1) ) : المصطلح العلمى ووحدة الفكر،اللغة العربية و الوعى القومى، مركز در اسات الوحدة العربية

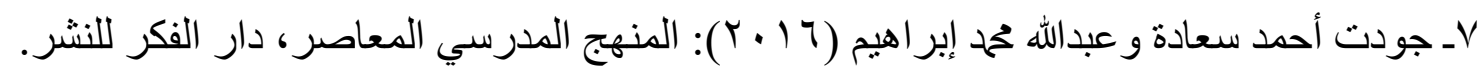
^ـ حامد عبد السلام زهران (1991 ()): علم نفس النمو ( الطفولة والمر اهقة)، ط ـ ، القاهرة، عالم الكتب. 9ـ حيدر مسير حمد الله وانصاف كامل منصور (11) (1) :أثر العصف الذهني فى النمو اللغوي لطفل الروضة، مجلة البحوث التربوية و النفسية، العدد آس، كلية التربية، جامعة بغداد $\underline{\text { www.iasj.net/isaj?func }=\text { issuetoc\&isId }+1951 \& u i l a n g u a g e=a r}$ • ـ ـ خالد عبد الر ازق (999 (199): اللغة بين النظرية و التطبيق، حورس للطباعة و النشر . 1) 


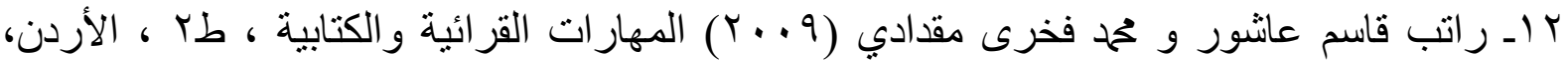
عمان، دار المسيرة للنشر و التوزيع . ب ـ زكريا أحمد الثربينى وآخرون( 919 () ) : رياضيات أطفال ما قبل المدرسة وأفكار جان بياجيه ، القاهرة، سلسلة در اسات الطفولة، مكتبة الأنجلو المصرية. ـ ـ ـ سعدية بهادر ( 99 ( )): برنامج تربية أطفال ما قبل المدرسة بين النظرية و التطبيق، القاهرة، مطبعة المدني. ا ـ سهير أحمد كامل (Y . . Y): سيكولوجية الأطفال ذوى الاحتياجات الخاصة ، مركز الإسكندرية للكتاب. ד ا ـ سهير عبد الفتاح وآخرون(9 . . ץ) : استر اتيجية تنمية لغة الطفل العربى، المجلس العربى للطفولة و التنمية.

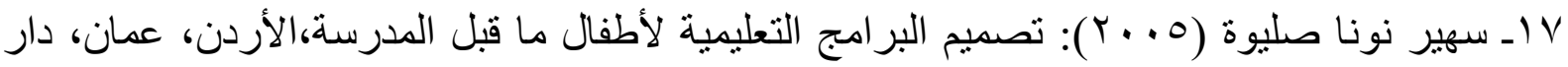
صفاء للنشر. 1 ا ـ عبد الفتاح أبو معال ( . . ץ): تنمية الاستعداد اللغوي عند الأطفال، القاهرة، الشروق. 9 ا ـ عدنان يوسف العتوم (ع . . ب): علم النفس المعرفي ،الأردن، عمان، دار المسيرة للنشر و التوزيع . • ؟ ـ علا عبد الرحمن على ( . . . ب): أثز بر امج الأطفال التليفزيونية على النمو اللغوي و المعرفي لأطفال ما قبل المدرسة، رسالة ماجستير، معهد الدر اسات و البحوث التربوية ،جامعة القاهرة.

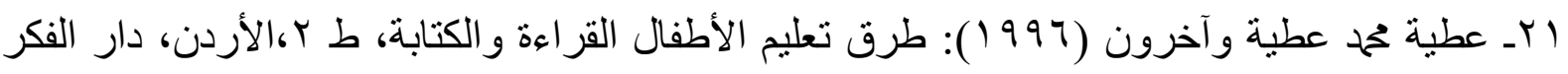
للنشر و التوزيع.

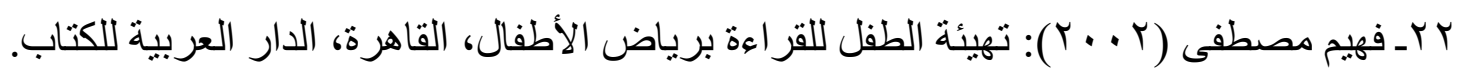
r ـ فهيم مصطفى (r . . r): مهار ات التفكير في مر احل التعليم العام رؤية مستقبلية للتعليم في الوطن العربي، القاهرة، مكتبة دار الفكر العربي. 
ع ז ـ كريمان بدير و إميلي صـادق ( . . . Y): تنمية المهار ات اللغوية للطفل،القاهرة، عالم الكتب .

ه ـ كمال الدين حسين ( צ991) : مدخل في مسرح ودر اما الطفل ، كلية رياض الأطفال، جامعة

ج ـ ـ ليلى كرم الدين (9 9 (1)): الحصيلة اللغوية المنطوقة لطفل ما قبل المدرسة من عمر عام حتى ستة أعو ام، الكويت، الجمعية الكويتية لتقدم الطفولة العربية. Y _ ماجدة محمود حمح صالح (991 (191): تأثير استخدام أنشطة الرياضيات لتنمية بعض عمليات التعلم الأساسية لدى طفل ما قبل المدرسة، الجمعية المصرية للمناهج وطرق التدريس، العدد 9 ؛، مايو.

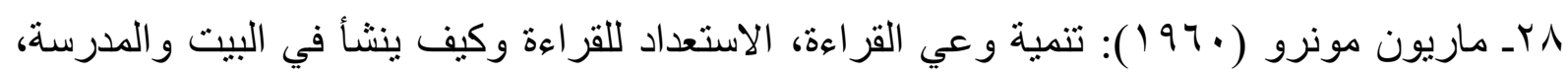
ترجمة سامي ناثد، القاهرة، دار المعرفة.

9 ب ـحمد رجب فضل الله (999 (19) : الألعاب اللغوية لأطفال ما قبل المدرسة ، القاهرة، عالم الكتب .

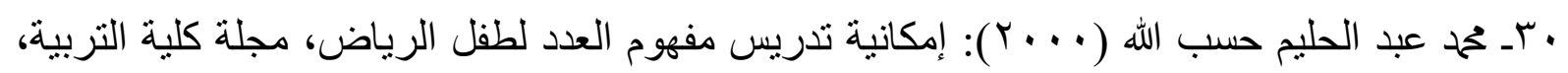
جامعة المنصورة، دمياط ، يناير ، اســ ححم عماد الدين اسماعيل (71911): الأطفال مرآة المجتمع ، النمو النفسي الاجتماعي للطفل فى سنو اته التكوينية، المجلس الوطني للتقافة و الفنون والأدب، عالم المعرفة، 99، الكويت، مارس.

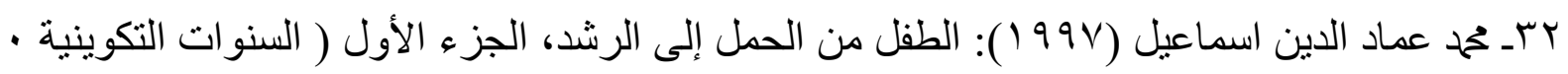
- 7 ( ) - (الكويت، دار القلم.

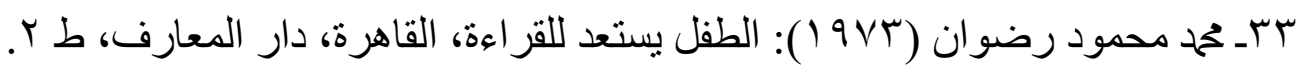
ع ـ محمود عبد الحافظ خلف الله (9 . . ץ): مرحلة ما قبل المدرسة هي أهم مراحل التشكيل الذهني http://.old.upu.edu.sa/page/ar/5367 للطفل: إذا استعصى عليك أمر ا فاستشر طفللك، هـ ـ معدر نو اف الهوارنة (r + . r): در اسة بعض المتغير ات المؤثرة في اكتساب اللغة لدى أطفال ما قبل المدرسة، رسالة ماجستير غير منشورة، معهد الدر اسات و البحوث التربوية، جامعة القاهرة. 


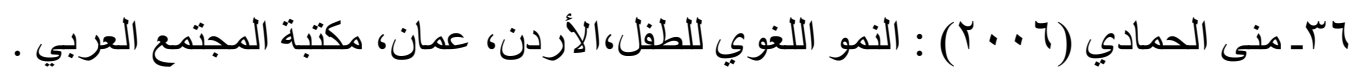

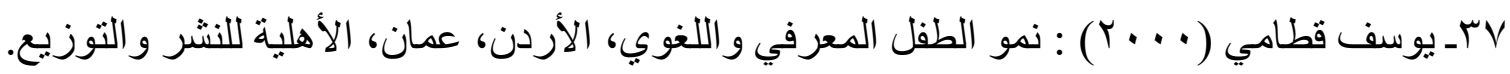
38 - gamification in Education (2016). Retrieved from : http:// www.learningtheories.com/gamification-in-education.html 39-Piaget ,J. (1970) .Piaget's theory .In Mussen .P.H.(Ed) Cormiehael's Manual of child psychology(voL.1) NEW YORK: Wiley.

40- Reutzel ,D\& Robert ,B. (1992) . Teaching Children to Read from basils to Books, Macmillan publishing Company, New York p . 312 .

41-Thorpe patricia, (1995) :spatial concepts Young Children, International, Journal Of Early Years. Education, vol.3,No2,Sum.

42 -https://www.mocaf.gov.ae/docs/default-source/default-document$\underline{\text { library/gamification_ar.pdf?sfvrsn }=0}$ 